\title{
Los problemas de validez en el análisis de redes sociales: Algunas reflexiones integradoras
}

\author{
J orge E. Miceli - U.B.A. ${ }^{1}$ (Argentina)
}

\section{Resumen}

El análisis de redes sociales ha venido para quedarse hace tiempo en las ciencias sociales. Sin embargo, la tendencia a considerarlo como un repertorio casi infalible de instrumentos de análisis es aún una tentación para sus practicantes y también para quienes no lo frecuentan pero ven en él una especie de quimera capaz de responder cualquier pregunta teórica relevante. A tono con estas reflexiones, presentaremos una división más o menos típica de las diferentes etapas que distinguen a una investigación de ARS para intentar dilucidar, en ellas, algunas de las problemáticas y decisiones metodológicas que pueden afectar seriamente la validez de los datos, cálculos e inferencias realizadas. Más allá de la especificidad técnica de las cuestiones que reseñaremos respecto al ARS, nos anima el objetivo más general de analizar sus peculiaridades bajo la perspectiva de cualquier proceso investigativo que tenga en cuenta premisas clásicas de la adquisición científica de conocimiento: integridad, pertinencia y representatividad de los datos, adecuación y alcance de las hipótesis manejadas, nivel de generalidad y consistencia deductiva de las conclusiones obtenidas, e incluso la factibilidad de generar modificaciones en el propio objeto de estudio con el fin de producir cambios ajustados a un determinado diseño de intervención.

Palabras clave: Validez, decisiones metodológicas, etapas investigativas, representatividad de los datos, consistencia deductiva.

\begin{abstract}
The analysis of social networks has come to remain long time in social sciences. Nevertheless, the tendency to consider it as an almost infallible repertoire of analysis instruments is still a temptation for its followers and also for those who do not frequent it but sees in it a kind of chimera able to respond any excellent theoretical question. According with these reflections, we will present a more or less typical division of the different stages that distinguish to an investigation of SNA to try to explain, in them, some of problematic and the methodologic decisions that can seriously affect the validity of the data, calculations and inferences. Beyond the technical specificity of the questions that we will review respect to the SNA, we have the most general objective to analyze its peculiarities under the perspective of any research process that considers a few classic topics of the scientific acquisition of knowledge: integrity, relevance and representativeness of the data, adjustment and reach of the handled hypotheses, deductive consistency of the obtained conclusions, and, finally, the possibility to generate modifications in the own object of study with the purpose of producing changes guided by a certain design of intervention.
\end{abstract}

Keywords: Validity, methodologic decisions, investigation stages, data representativeness, deductive consistency.

\footnotetext{
${ }^{1}$ Enviar correspondencia a: jorgemiceli@hotmail.com
} 
REDES- Revista hispana para el análisis de redes sociales

Vol.14,\#1, Junio 2008

http: // revista-redes. rediris.es

\section{I ntroducción}

El análisis de redes sociales ha venido para quedarse hace tiempo en las ciencias que llamamos blandas. Su evidente dimensión epistemológica y teórica ya no ofrece espacio para la discusión y a nadie se le ocurriría presentarlo, a esta altura del partido, como una simple colección de instrumentos y técnicas adosables a cualquier perspectiva.

Sin embargo, la tendencia a considerarlo como un repertorio infalible de herramientas de análisis es aún una tentación para sus practicantes y también para quienes no lo frecuentan pero ven en él una especie de quimera capaz de dar respuestas fundamentadas a cualquier pregunta de investigación.

Efectivamente y como bien sostiene Carlos Lozares:

El ARS se presenta, a veces, como una caja de herramientas de naturaleza técnico-formal y/o gráfica en la búsqueda pragmatista y eficaz de resultados sin que se dé una reflexión suficiente sobre las condiciones y situaciones de recogida de información o sobre la naturaleza de los datos y su contextualización o sobre las dimensiones cognitivas, fácticas, dinámicas, simbólicas etc. que supone la relación social o sobre los campos en los que se insertan dichas relaciones (Lozares 2005: 1).

Varios factores sustentan esta forma de ver las cosas. Creemos que algunos de ellos tienen que ver con la historia misma de este enfoque, basado tempranamente en la teoría de grafos y en los estudios sociométricos de Moreno, los cuales le dieron un status de rigurosidad que fácilmente habilitó dos visiones opuestas pero convergentes en sus efectos negativos: o hubo una negación a incorporar los beneficios del ARS debido a una incomprensión de su base técnica, o esta base técnica se constituyó en un aparato de validación supuestamente autónomo y hasta cierto punto inmune a los exámenes de rigurosidad por el que deben pasar perspectivas menos dependientes de un lenguaje fuertemente operacionalizado.

La negación a sumergirse en los desafíos del ARS por motivaciones que podemos calificar como pre-teóricas, basadas en prejuicios antipositivistas o en posiciones conceptuales que genéricamente podríamos calificar como posmodernas, no va a ser objeto de ningún comentario en este espacio. La inmensa productividad del análisis de redes sociales en su faz práctica, su desbordante pertinencia transdisciplinaria y la gran cantidad de problemas que permite resolver o al menos describir de manera infinitamente más innovadora que desde perspectivas no 
REDES- Revista hispana para el análisis de redes sociales

Vol.14,\#1, J unio 2008

http: // revista-redes. rediris.es

reticulares, nos eximen de tener que ensayar una defensa de su utilidad frente a detractores tan poco sustanciosos².

Sin embargo, la sobreestimación o la consideración no contextualizada de su potencialidad técnica también nos deparan consecuencias simétricamente negativas. Es muy común que cuando se llevan a cabo cursos de ARS, se empiece, por ejemplo, diciendo que una cosa es el uso técnico de los conceptos y otra muy distinta la apelación metaforizada o sustantiva que se hace de ellos desde ciertas corrientes no expertas. Rápidamente, el criterio de demarcación que se aplica en estos casos obliga luego a situarse del lado técnico del mostrador y a deslindarse de descripciones poco empapadas del vocabulario que los analistas de redes sociales manejan con cierta comodidad.

De este modo, el uso de palabras como intermediación, cercanía o cliqués, o sus versiones en inglés, pasan a garantizar y a probar que quien habla del tema es de

2 Para abonar con referencias más precisas esta idea de la importancia contemporánea del ARS, tengamos en cuenta que desde el año 1978 existe INSNA (International Network for Social Network Análisis), organización sin fines de lucro capaz de concentrar los esfuerzos de cientos de investigadores en el area del ARS (http://www.insna.org/INSNA/insna_inf.html). La revista Connections (Ver http://www.insna.org/indexConnect.html), la publicación oficial del INSNA, existe desde 1977 y se ha convertido en un claro referente de los estudios de Análisis de Redes Sociales a nivel mundial, proyectando la especialidad a una instancia verdaderamente interdisciplinaria y operando como punto de encuentro entre profesionales que incluso no provienen de las ciencias sociales. Desde el año 1997, además, existe el International Sunbelt Social Network Conferences, instancia anual en la que se reúnen especialistas de esta disciplina y en donde se afinan criterios metodológicos y epistemológicos que luego sirven de parámetro a los investigadores de todo el mundo. Como dato de interés cabe consignar que la revista electrónica Redes (Ver http://revista-redes.rediris.es/), que nuclea a los investigadores de ARS de habla hispana, muestra un dinamismo creciente y una evolución comparable a la del INSNA.

Específicamente en la antropología, campo que nos preocupa por nuestro origen profesional, los aportes del Análisis de Redes Sociales han sido numerosos y de incidencia prematura, y desde los usos pioneros de esta metodología quedó en claro su enorme capacidad para inspirar desarrollos teóricos alejados de la perspectiva tradicional. Esta es quizás una historia no tan conocida como la que vincula al ARS con la sociología, pero el caso es que el antropólogo John Barnes fue el primero en utilizar el análisis de redes explícitamente en su estudio "Class and Committees in a Norwegian Island Parish" en una época tan temprana como el año 1954 (Rivoir 1999:3).

En esta investigación, Barnes describió el sistema social de la aldea de Bremnes, una pequeña comunidad noruega de pescadores y granjeros, y distinguió tres campos sociales; el sistema territorial, el industrial y un tercero constituido por el parentesco, la amistad y otras relaciones. Es en el análisis de este último ámbito, caracterizado por vínculos continuamente cambiantes y sin organización estable ni coordinación global, en el que este investigador utiliza un concepto de red que responde a la definición analítica e instrumenta de la que hoy en día echamos mano:

“La imagen que tengo es de un conjunto de puntos algunos de los cuales están unidos por líneas. Los puntos de la imagen son personas o a veces grupos, y las líneas indican que individuos interactúan mutuamente. Podemos pensar claro está, que el conjunto de la vida social genera una red de este tipo" (citado de Rivoir 1999:3).

Otro trabajo de aproximadamente la misma época (1957) fue desarrollado por la antropóloga Elizabeth Bott, quien, en "Family and Social Network", establece una sugestiva correlación entre el tipo de vínculo que establecen maridos y mujeres y la clase de sociedad en la cual se desempeñan.

Estas investigaciones pusieron tempranamente el foco en temas que luego serían la punta de lanza para el desarrollo del ARS. El desarrollo de las relaciones informales, especialmente apto para el enfoque reticular, es también el campo ideal para la experimentación etnográfica, y creo que esta no es, en términos epistemológicos, una afinidad menor. 
REDES- Revista hispana para el análisis de redes sociales

Vol.14,\#1, Junio 2008

http: // revista-redes. rediris.es

alguna forma un especialista perfectamente a salvo de la ignorancia de los legos. EI apoyo de mucho software de base, de papers saturados de tecnicismos y de impactantes representaciones matriciales y gráficas confirma y acentúa este efecto de encantamiento conceptual, cosechando a veces incondicionales adeptos mucho más allá, a nuestro entender, de los necesarios reparos que los cientistas sociales deben tener no sólo frente a desbordantes ejercicios de retórica académica, sino también, e incluso más fundamentalmente, frente a aparatos descriptivos y explicativos repletos de notaciones complejas o despliegues numéricos o algebraicos que parecen convencer por sí solos.

Por supuesto que no está mal que el ARS opere con base en un vocabulario fuertemente técnico y que sus discusiones se diriman en el pertinente espacio de los datos procesados por programas como Ucinet, Pajek o NetDraw o por paquetes de software más modernos y específicos. Ese es el mérito principal de este campo de análisis, su logro más resonante y el valor agregado que cualquier científico social le adjudica. Creo, sin embargo, que esto no debe hacernos pensar que la tarea está por eso cumplida y que las investigaciones que acuden al Análisis de Redes Sociales están a salvo de los problemas de validación y de los errores que afectan a cualquier investigación standard. No es que alguien proponga semejante cosa explícitamente, pero esta suposición de relativa incuestionabilidad puede inferirse de la forma en que se presentan la mayoría de las investigaciones de ARS; el grueso de las exposiciones se centra en el cálculo de medidas de la red y de los grupos que la conforman, en las implicancias que esta morfología tiene para los procesos sociales que en última instancia están en el foco teórico del análisis, pero en muy pocas ocasiones se reflexiona sobre la arbitrariedad de los procesos de selección de datos, sobre su alcance condicional y sobre el enorme conjunto de definiciones operacionales que están controlando y habilitando la mayoría de los mecanismos de inferencia a los cuales se apela.

Es fácil observar, en este sentido, una especie de naturalización metodológica que de alguna forma oculta, mediante el uso del instrumental técnico y terminológico, la problemática de la validez relativa de las conclusiones que se obtienen en cada investigación.

Mi propósito no es, en este sentido, ni meramente impugnatorio ni prolijamente exhaustivo.

No es lo primero porque a la par que intento echar luz sobre lo problemáticas que resultan ciertas elecciones metodológicas, no pretendo contentarme con 
REDES- Revista hispana para el análisis de redes sociales

Vol.14,\#1, Junio 2008

http://revista-redes. rediris.es

enunciarlas sino que trato de sugerir algunos modestos caminos para su abordaje. Tampoco es lo segundo porque hay problemas de validez que no reseñamos y que seguramente se podrían agregar a este inventario en un proceso recursivo casi infinito.

En términos más generales, también intento llamar la atención sobre el carácter bien clásico de los problemas que enfrenta una investigación de ARS sea cual sea el alcance teórico, el tipo de datos del que disponga y la naturaleza general del objeto con que se enfrente. Creo que la mayoría de las cuestiones que aquí toco, abstrayéndome del objeto de estudio y de la terminología a la que apelo, pueden observarse claramente en investigaciones no reticulares y aún en diseños experimentales o exploratorios bastante alejados de las ciencias sociales. Es necesario, sin embargo, apreciar como estos temas adquieren un formato muy puntual en el ARS, un formato muchas veces disimulado o inadvertido tras la parafernalia analítica y algorítmica facilitada tanto por la perspectiva teórica como por el software de apoyo provisto por esta subdisciplina.

\section{El universo social representado como Objetos, Atributos y Relaciones: La generalidad de esta perspectiva y su aplicación al ARS}

Ya es casi un lugar común afirmar que no hay definición operacional de ningún objeto de estudio que no involucre abstracción de variables y relaciones. La apelación retórica al concepto mismo de "reflexividad" de Pierre Bourdieu, por ejemplo, se ha conformado, en la antropología y también en algunas perspectivas sociológicas, en un recurso casi salvador al momento de incluir cualquier investigación en cuestión en el conjunto de aquellas que no pierden de vista lo problemático de esta selección del objeto. Sólo si se es lo suficientemente reflexivo, pareciera que se nos dice, se evita la arbitrariedad de pensar que las entidades discursivas o modélicas que estamos manipulando son la realidad misma en toda su extensión y complejidad, y no su representación sesgada y operativa. Yendo más allá pareciera ser que, desde esta perspectiva, solo ciertas maniobras lingüísticas aseguran de por sí el ingreso al olimpo de las teorías concientes de estas dificultades y capaces de evitarlas. El complejo problema de los errores e inadecuaciones de método, de las generalizaciones con escasa base empírica o de los saltos lógicos de la inducción a la deducción es reducido a una especie de 
REDES- Revista hispana para el análisis de redes sociales

Vol.14,\#1, Junio 2008

http://revista-redes. rediris.es

recomendación de que seamos reflexivos y de que ejercitemos la reflexión epistemológica en todo momento ${ }^{3}$.

El inconveniente insalvable, me parece, es que no basta con conocer los obstáculos y dilemas del proceso investigativo y declamar este conocimiento para lograr la neutralización de sus efectos negativos, distorsionadores o invalidantes. En términos más prácticos, digamos que no es suficiente saber que estamos tomando unos aspectos y dejando de lado otros cuando representamos cualquier entidad del mundo real. Es necesario, en la medida de nuestras posibilidades, conocer e inventariar estas selecciones tanto para relativizarlas y modificarlas si se puede, como para ser precavidos en la obtención de conclusiones a partir de ellas.

El análisis de redes sociales, con toda su batería de métodos de análisis y cálculos, por supuesto que no escapa a las generales de esta ley. Siempre hay, al menos, cuatro etapas de selección y procesamiento de la información que operan sucesivamente (aunque con cierto solapamiento) y que llevan a la construcción supervisada de una red. Habría una quinta etapa, la de intervención, en la cual se opera sobre ella y que también incluiremos en el análisis. ¿Qué es lo común a estas etapas?

En primer lugar, todas parten de un insumo investigativo previo y generan un producto que será retomado como insumo en una etapa posterior. Desde ya que los límites entre ellas no son tan claros y que lo que propongo es solo una abstracción con fines bien didácticos, pero sostengo que la utilidad de este corte es relevante si pensamos en que, a grandes rasgos, puede ser aplicado a cualquier investigación.

\footnotetext{
${ }^{3}$ No hace falta plantear -y hacerlo además de presuntuoso sería inexacto- que este uso desviado de la idea de reflexividad es un hallazgo propio. El propio Bourdieu se encarga de poner las cosas en su lugar cuando critica los usos espúreos que de este término se hacen. Lo interesante es que, aunque sus interlocutores explícitos suelen ser más los sociólogos que los antropólogos, en este caso algunos de los destinatarios directos de su crítica son los antropólogos de extracción posmoderna.

Según comenta él mismo:

“La sociología de la sociología que defiendo no tiene nada que ver con el retorno intimista y complaciente sobre la persona privada del sociólogo, ni de la explicitación del Zeitgeist intelectual que inspira su trabajo, a la manera del análisis de Parsons que propone Gouldner en su "The Coming Crisis of Sociology". Tampoco me reconozco en la «reflexividad» entendida como esa especie de observación del observador, hoy en boga entre ciertos antropólogos americanos (por ejemplo Marcus, Fisher, Geertz y Rosaldo), quienes, habiendo agotado en apariencia los atractivos del trabajo de campo, se han puesto a hablar de sí mismos antes que de su objeto de estudio" (Bourdieu, 1992: 52, citado de Gilberto Giménez 1997).
} 
REDES- Revista hispana para el análisis de redes sociales

Vol.14,\#1, Junio 2008

http: // revista-redes. rediris.es

En segundo lugar, cada etapa está sujeta a decisiones metodológicas guiadas tanto por inquietudes del investigador como por factores de selección y procesamiento de la información que son externos a él. Estas decisiones tienen un distinto nivel de adecuación respecto de las preguntas e hipótesis que el investigador se plantea. Una decisión metodológica inadecuada, como se verá, puede dificultar o imposibilitar el desarrollo posterior de la investigación. Los datos o análisis obtenidos pueden ser correctos o consistentes, pero irrelevantes o no pertinentes para las hipótesis y preguntas planteadas en cada caso.

En tercera instancia, hay errores e insuficiencias que afectan a cada fase y que, si no se corrigen, generan una propagación o una herencia del problema a las siguientes etapas. Aunque se tome la decisión metodológica adecuada, la implementación de esa decisión puede ser defectuosa y afectar con distintos grados de severidad la validez de los resultados obtenidos.

\subsection{Recoleccion de Datos}

Nunca se recolecta toda la información que se puede recolectar: Los sesgos teóricos y metodológicos y la accesibilidad actúan haciendo que se releven solo ciertos aspectos y porciones de los datos.

Nodos y lazos son las entidades primarias que permiten mapear una red social, pero su misma inclusión implica un proceso selectivo bastante escamoteado y naturalizado en las investigaciones de rigor. Estos objetos no "devienen" naturalmente de observar la realidad, sino que deben ser conceptualizados, recortados de una masa de eventos mucho más amplia y heterogénea, e incluso la misma utilidad de su consideración debe ser chequeada luego y en referencia a los mismos requerimientos de cada investigación. Muchas veces, en esta etapa que se puede denominar "recolección", se parte de un diseño experimental que luego resulta ser inadecuado para las necesidades de análisis del momento. No se trata aquí de que algunas representaciones sean más veraces que otras, sino de su pertinencia específica respecto a preguntas puntuales que queremos responder. $\mathrm{Si}$ uno se propone analizar el intercambio comercial entre países, por ejemplo, no tiene sentido que se mapee también el flujo de personas en viajes entre cada uno de ellos. Más allá de que el dato esté disponible o no (puede ser que no exista y haya que conseguirlo laboriosamente), el mapeo que hacemos es de por sí selectivo y sujeto desde el comienzo a nuestros intereses investigativos generales 0 particulares. 
REDES- Revista hispana para el análisis de redes sociales

Vol.14,\#1, Junio 2008

http: // revista-redes. rediris.es

¿Cuál es el fundamento general de esta selectividad? ¿Qué aspectos rigen la elección de aquellas entidades susceptibles de transformarse en el foco de un estudio de redes sociales?

\subsubsection{El aspecto "emic" y "etic" en el mapeo del universo de datos del ARS}

Una distinción que ha sido bastante transitada en la antropología y el trabajo etnográfico, por malos o buenos motivos, es la existente entre las conceptualizaciones "etic" y "emic" de la cultura. Emparentada estrechamente con los trabajos de Roman Jakobson sobre el funcionamiento de los sistemas fonológicos, pero formulada originalmente por el lingüista y misionero Kenneth Pike en el año 1954 para dar intentar dar cuenta de la cultura desde un punto de vista interno, la diferencia entre estas dos visiones no es presentada por neutralidad por Pike, sino puesta al servicio de un proyecto bastante más ambicioso que consiste en construir, como sostiene Carlos Reynoso:

Una visión capaz de brindar una especie de ciencia unificada, o la posibilidad de la unificación de las ciencias, o por lo menos de las sociales. Las ciencias humanas, la historia, la sociología, la antropología, según Pike, iban a quedar en algún momento subsumidas bajo el punto de vista emic. En algún momento se iba a reconocer que cada cultura, cada sociedad, cada lengua, cada período histórico solamente podrían ser comprendidos en sus propios términos poniendo entre paréntesis, para emplear una metáfora fenomenológica, todos los conocimientos o todos los supuestos previos que lleva el estudioso de Occidente académicamente formado (Reynoso 1998:17).

En principio creo que este proyecto de ciencia unificada y basada en una percepción emic de la cultura, a pesar de originarse en un programa de investigación básicamente fallido, guarda una fuerte relación con las distintas formas de generar datos que el Análisis de Redes Sociales utiliza.

Para Pike lo etic es lo intercultural antes que lo específico de una cultura, las unidades de análisis disponibles de antemano más que aquellas determinadas por el análisis, y una concepción externa o extraña a la naturaleza de lo que se estudia más que una basada en una percepción interior y estructurada por el mismo sistema en estudio (Reynoso 1998: 14) ${ }^{4}$.

\footnotetext{
${ }^{4}$ No incursionaremos en los pormenores de esta dicotomía, pero podemos convenir en que planteada de esta forma, y como Reynoso mismo lo señala, esta contraposición, muestra demasiadas inconsistencias como para ser tomada como parámetro de referencia absoluto de una investigación etnográfica (Reynoso 1998: 15).

Siguiendo estos lineamientos críticos, algo básico que no nos queda en claro si lo etic o emic concierne al origen de los datos, a una inherente ontología de ellos o a distintos criterios elegibles para su conceptualización.
} 
REDES- Revista hispana para el análisis de redes sociales

Vol.14,\#1, J unio 2008

http: // revista-redes. rediris.es

Esta distinción, que dentro y fuera de la antropología tiene aspectos taxonómicos e implicancias teóricas muy problemáticas y discutibles, ofrece desde mi punto de vista una buena base para hablar de dos tipos de redes que a menudo se mezclan en los trabajos de ARS: las redes percibidas y las redes observadas.

En efecto, a veces pareciera que ambas son lo mismo o que el ámbito de validación de su existencia es similar, pero hablamos de constructos analíticos completamente diferentes. Una red percibida está sustentada en lo que uno o más participantes pueden decir de sus contactos en un grupo social, y reconoce como ámbito de validación la opinión de los propios integrantes. Una red observada está basada, en cambio, en lo que el investigador puede establecer sobre los intercambios, lazos o percepciones que los nodos muestran, y su ámbito de validación son sus propios criterios de mapeo, que deben ser públicos y detalladamente explícitos ${ }^{5}$.

Esto quizás pueda pensarse mejor de cara a un ejemplo. Si deseamos representar las percepciones que las personas tienen de otras personas de su círculo cercano de relaciones, podemos usar estrategias metodológicas muy distintas.

Podemos preguntarle a la gente directamente sobre el tema, u observarla interactuar para sacar nuestras conclusiones. En términos de las conceptualizaciones que hemos hecho, el primer enfoque sería etic y el segundo emic. Lo interesante es que, por varios motivos, puede haber serios desajustes entre los resultados de ambos enfoques. Más específicamente y en relación a las causas de esta divergencia, hay dos grandes conjuntos de ellas: o efectivamente las personas perciben distinto al modo en que actúan, y esto mismo puede ser objeto de análisis, o los criterios de los cuales parten investigadores y encuestados son distintos y no se ha reflexionado sobre ello.

Respecto del primer caso hay que tener presente que, a efectos de entender el despliegue de las conductas reales, el modo en que las personas perciben su red de relaciones puede ser tanto o más importante que los vínculos realmente existentes. Al contrario que en la mayoría de las redes no sociales (físicas, químicas, etc.), en

\footnotetext{
${ }^{5}$ Antes que nada notemos que esta simple dicotomía nos permite diferenciar al Análisis de Redes Sociales del Análisis de Redes a secas. En efecto, en el segundo, que puede aplicarse a redes biológicas, inorgánicas, electrónicas etc., pero no a personas, nunca mapearemos percepciones, y siempre optaremos por representar redes observadas. Esto, valga la pena acotarlo, no implica que necesariamente seamos más "objetivos" o "rigurosos" que si estudiamos redes percibidas. Se puede ser todo lo subjetivo, antojadizo y arbitrario que se quiera representando una red observada, pero la forma en que, como científicos sociales, podremos cuestionar su veracidad, es examinando los criterios de mapeo de datos y viendo sus deficiencias, o reutilizándolos atentamente por cuenta propia de cara a la misma información o a datos estructuralmente equivalentes.
} 
REDES- Revista hispana para el análisis de redes sociales

Vol.14,\#1, Junio 2008

http: // revista-redes. rediris.es

las redes sociales el dominio informacional de cada nodo (su horizonte perceptivo o comunicacional), constituye una instancia causal que genera conductas hasta cierto punto autónomas respecto de la topología de la red.

Respecto de la segunda causa de divergencia, centrada en los criterios diferenciales adoptados por investigadores y encuestados respecto de un mismo tema, opino que es necesario ponerla en el centro del debate e indagar cual de las dos perspectivas tiene mayor relevancia al momento de explicar conductas dentro de la red. El problema no es trivial porque el comportamiento de los nodos puede potencialmente ajustarse a cualquiera de los dos criterios y ambas realidades ofrecerían un fuerte interés teórico e investigativo. Si la gente actúa de acuerdo a parámetros que ignoran total o parcialmente la estructura de la red observada, entonces sería válido concentrarse en los aspectos emic de la cuestión si queremos tener alguna capacidad predictiva. ¿Qué factores contribuyen a la existencia de esta distorsión cognitiva en la percepción de la red real? ¿Es posible correlacionar este desvío con características específicas de la red bajo estudio? De un modo inquietante, también cabe preguntarse si el comportamiento de cada nodo obedece a cuestiones exclusivamente relacionales. $\mathrm{Si}$ es verdad que tenemos una perspectiva epistemológicamente abierta, nuestro uso del ARS no debe limitarnos al momento de intentar explicar comportamientos en la red mediante factores no exclusivamente relacionales. Nótese que no estamos haciendo, en definitiva, otra cosa que desvincular conceptualmente suposiciones de identidad muy comunes en el ámbito del ARS. Por un lado, identidad absoluta entre red observada y red percibida y por el otro, entre comportamiento relacional y causalidad exclusivamente relacional.

\begin{tabular}{|c|l|l|l|}
\hline & \multicolumn{1}{|c|}{ Red real (RR) } & Red observada (RO) & \multicolumn{1}{c|}{$\begin{array}{c}\text { Red percibida } \\
\text { (RP) }\end{array}$} \\
\hline Ontología & $\begin{array}{l}\text { Relaciones existentes } \\
\text { en el universo } \\
\text { empírico }\end{array}$ & $\begin{array}{l}\text { Subconjunto de } \\
\text { Relaciones observadas y y } \\
\text { mapeadas por el } \\
\text { investigador }\end{array}$ & $\begin{array}{l}\text { Subconjunto de Relaciones } \\
\text { percibidas por los nodos y } \\
\text { mapeadas por el investigador }\end{array}$ \\
\hline $\begin{array}{l}\text { Método de } \\
\text { obtención }\end{array}$ & $\begin{array}{l}\text { No hay acceso } \\
\text { metodológico directo }\end{array}$ & $\begin{array}{l}\text { Representación externa } \\
\text { de observaciones }\end{array}$ & $\begin{array}{l}\text { Representación externa de } \\
\text { opiniones o percepciones de } \\
\text { los actores }\end{array}$ \\
\hline $\begin{array}{l}\text { Trayecto } \\
\text { analítico }\end{array}$ & $\begin{array}{l}\text { 1)Red real } \rightarrow \\
\text { 2) Representación hecha } \\
\text { por el Investigador }\end{array}$ & $\begin{array}{l}\text { 1) Red real } \rightarrow \\
\text { 2) Representación hecha por } \\
\text { los integrantes } \rightarrow \\
\text { 3) Representación hecha por el } \\
\text { Investigador }\end{array}$ \\
\hline
\end{tabular}

Tabla 1. Tipos de redes. 
REDES- Revista hispana para el análisis de redes sociales

Vol.14,\#1, Junio 2008

http: // revista-redes. rediris.es

En la Tabla 1 presentamos un intento de visión integradora de estas entidades. Siguiendo este esquema, el pasaje de la red real (RR) a la red observada (RO) se produce necesariamente en cualquier proceso de investigación a través de las hipótesis y el diseño de investigación propuesto por el especialista. Es importante no caer en un empirismo ingenuo y sostener que tenemos un acceso transparente y absoluto a la red real. Este acceso no es transparente porque media nuestro aparato teórico y nuestros preconceptos en el recorte de que echemos mano, y no es absoluto porque mapearemos solo una parte de las relaciones existentes y en un momento del tiempo.

En estos términos, la RO constituye una representación de primer orden de la red real en tanto el investigador recolecta e interpreta información existente en relaciones que pueden percibir sin intermediarios. Un ejemplo clásico son las relaciones económicas entre países. La RP, en cambio, es una representación de segundo orden en la medida en que es una representación de la representación hecha por los integrantes de la red. El foco de ella no es el universo relacional, sino el modo en que este es percibido por la gente.

2.1.2 El problema de la definición de la red a través del mapeo de lazos o por comunidad de atributos

Otra cuestión central en la etapa de recolección de datos es la manera en que definiremos el universo relacional total de nuestra red. Siendo un tanto taxativos, podemos decir que hay dos maneras básicas y generales de hacerlo. 0 consideramos, a priori, que solo los nodos que tienen determinadas características forman parte de la red (definición atributiva), u obtenemos la red como producto de recolectar lazos suministrados por los mismos actores.

Ambas metodologías tienen sus ventajas y desventajas, y nuevamente el investigador es quien tiene que tomar importantes decisiones al respecto.

La definición atributiva de una red podría ser equiparable a una concepción etic de la misma, ya que parto del supuesto de que sólo los nodos que cumplen determinados requisitos formarán parte de ella. No me interesa aquí verificar si esos nodos están conectados en mayor o menor medida con el resto de la población. La definición de la red por mapeo de lazos, en cambio, responde a criterios estrictamente reticulares en la conformación de una estructura de relaciones. En otros términos, podemos decir que en esta segunda opción no me interesa tener en cuenta las características de cada nodo para saber si formará parte de mi red. Solo si tiene vínculos con otros nodos formará parte de la misma. 
REDES- Revista hispana para el análisis de redes sociales

Vol.14,\#1, Junio 2008

http: // revista-redes. rediris.es

Por ejemplo, si quiero mapear la red de relaciones entre los operadores políticos de determinada ciudad, el criterio atributivo demandará primero hacer una lista de aquellas personas que, en virtud de su filiación partidaria, puedan ser considerados a priori en esa situación. Cumplido este paso, podríamos pasar a tener en cuenta el modo en que efectivamente si vinculan entre sí (si quisiésemos armar una red de un modo) o entre sí mismos y con el resto de la población (si trabajáramos con redes de dos modos). En virtud de este criterio, algunos operadores seguramente mostrarán más vínculos, otros un conjunto menor de relaciones, y existe, sobre todo, la posibilidad de que algunos de ellos, a pesar de ser considerados a priori en esta categoría, no tengan relaciones ni con otros operadores ni con el resto de la población.

Si escogiésemos un camino estrictamente relacional las cosas serían bastante distintas, ya que, como venimos anticipando, solo incluiríamos en la red a aquellos actores que efectivamente sean reportados en alguna instancia como integrantes de ella.

Un claro ejemplo del primer criterio es el seguido en el trabajo de las familias florentinas de John Padgett ${ }^{6}$, en el que la familia Pucci, a pesar de participar de la investigación y como vemos en la llustración 1, no muestra vínculos en la red de relaciones maritales.

\footnotetext{
${ }^{6}$ Este trabajo de investigación, que alcanzó la categoría de "clásico" en el análisis de redes sociales, se desarrolló en varias etapas y combinó un detallado trabajo de recolección de datos con un mapeo posterior de redes de distinto tipo. Básicamente se representaron relaciones de parentesco, de vinculación financiera y de participación política de 16 familias de la ciudad italiana de Florencia en un lapso de dos siglos.
} 
REDES- Revista hispana para el análisis de redes sociales

Vol.14,\#1, Junio 2008

http: // revista-redes. rediris.es

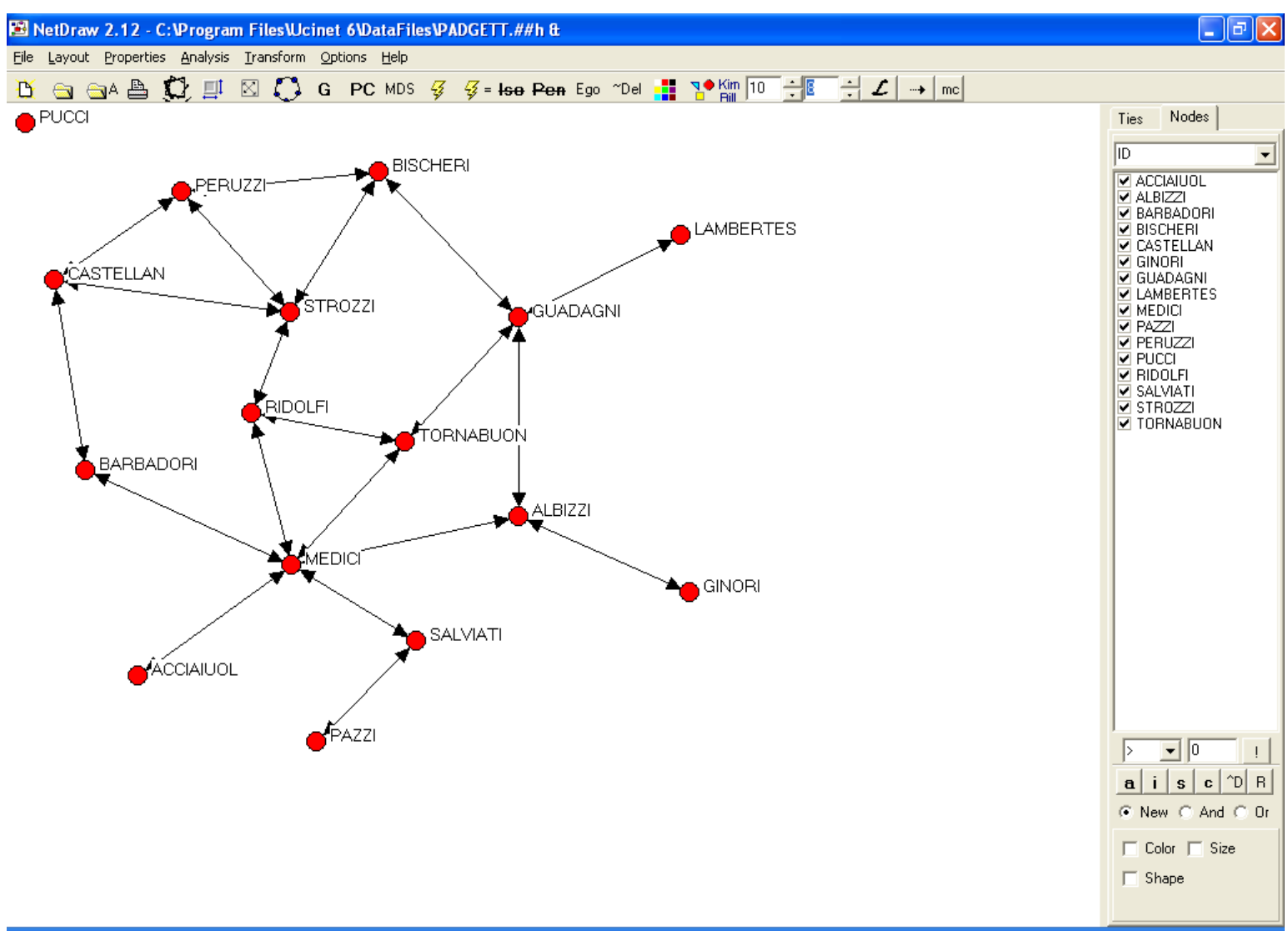

I lustración 1. Red de Familias Florentinas de Padgett que muestra el aislamiento parental de la familia de los Pucci.

Esta red, que por cierto retomaremos en los siguientes ejemplos, consta de más de un tramado de relaciones que incumben a la misma población de nodos. No solamente se ha recolectado información sobre relaciones maritales, sino también sobre vínculos políticos e intercambio de riqueza ${ }^{7}$. El hecho de que en una de las redes uno o más nodos queden aislados puede atribuirse, en este caso, a que se han decidido relevar relaciones de distinto tipo teniendo como protagonista al mismo conjunto de actores. No en todos los mapeos reticulares que fueron producto de la misma investigación la familia Pucci no tiene vínculos con el resto, pero al menos es así en uno de los casos. ¿Tiene sentido representar una estructura relacional en la que algunos nodos tengan conectividad nula? $\mathrm{Si}$ queremos incluir como factor de contraste esta situación respecto de la de otros nodos vinculados tal vez tenga utilidad hacerlo, pero, como diremos hasta el hartazgo, no hay respuestas unívocas a estas preguntas ni a otras que aquí planteamos.

\footnotetext{
${ }^{7}$ Técnicamente, y al menos para quienes no están familiarizados con la terminología del ARS, tal vez no esté de más señalar que estamos ante una red multirrelacional.
} 
REDES- Revista hispana para el análisis de redes sociales

Vol.14,\#1, Junio 2008

http: // revista-redes. rediris.es

Lo importante a tener en cuenta, en este caso, es que la definición por atributos ofrece la posibilidad de visualizar las relaciones preexistentes y otorgarles un peso analítico que de otra forma no tendrían.

Por otro lado, establecer una red con base en la existencia estricta de lazos ofrece el riesgo metodológico opuesto al que estamos describiendo. El método de recolección conocido como "bola de nieve", naturalmente emparentado con esta opción, quizás nos permite generar una trama de vínculos mucho más contraintuitiva o novedosa que la prevista por una definición atributiva y apriorística de la red, pero también nos puede llevar a subvalorar la importancia de nodos que no participan de las redes mapeadas pero que si forman parte de relaciones que se complementan estrechamente con ellas.

En realidad creo que las definiciones atributivas o relacionales de la red, que son no solo distinciones ontológicas sino además dispositivos de generación de las estructuras relacionales, deben ser vistas como complementarias y no como irreductiblemente opuestas. En ningún caso, me parece, deberían llevarse al extremo y excluir maneras mixtas o combinadas de ver las cosas.

\subsubsection{La irreversibilidad metodológica de la dicotomización}

En principio es verdad que las propias preguntas e hipótesis nos van guiando respecto al tipo de datos que vamos a recolectar, pero hay que considerar que si se obtiene información muy general o con escaso nivel de agregación, luego será imposible o muy difícil volver hacia atrás y conseguir más detalle de aquello que nos interesa.

Concretamente, si por ejemplo se relevan datos ya dicotomizados (existencia o inexistencia de un vínculo), será imposible trabajar luego con información valuada de ellos, cosa que no sucede a la inversa, ya que datos valuados pueden dicotomizarse luego y así disponer de al menos dos representaciones alternativas de la red. No solo existe esta posibilidad, sino que sería posible establecer diferentes umbrales de dicotomización para obtener distintas imágenes de los vínculos, como observamos en la siguiente red obtenida de las investigaciones de Freeman sobre interacciones y mensajes entre investigadores (Freeman 1979): 
REDES- Revista hispana para el análisis de redes sociales

Vol.14,\#1, Junio 2008

http: // revista-redes. rediris.es

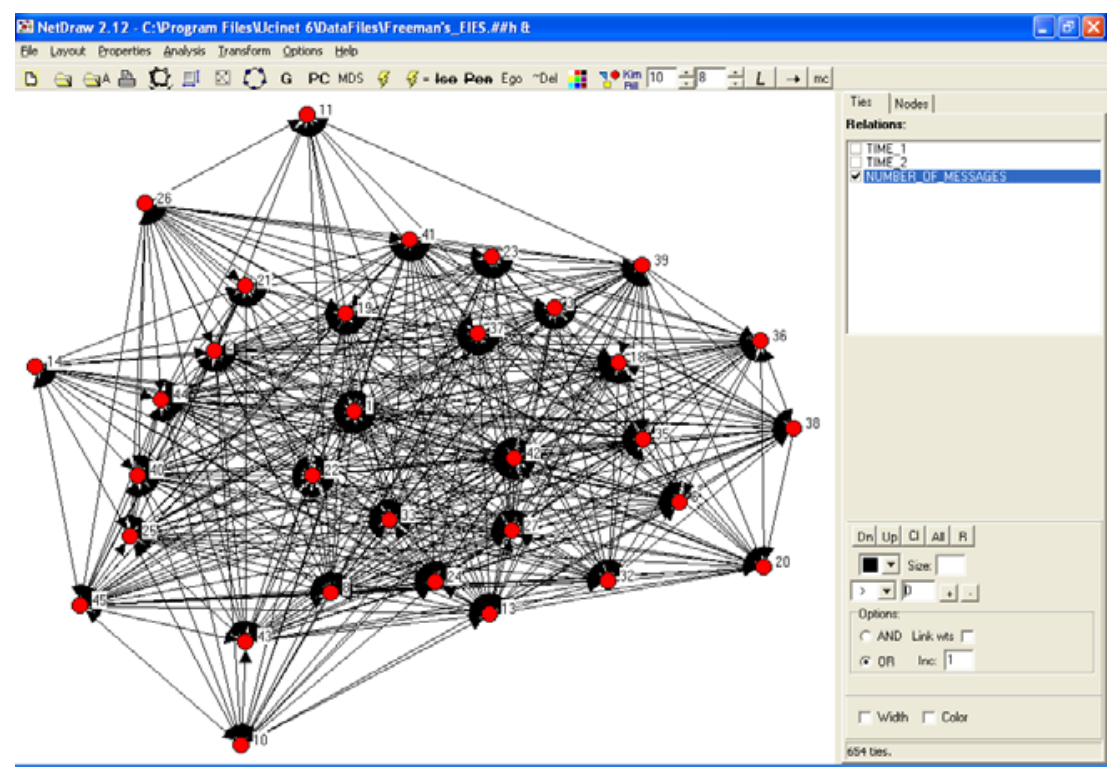

I lustración 2. Redes de intercambio de mensajes de Freeman dicotomizadas a un valor de 0.

Si el umbral de dicotomización es 0 , como mostramos arriba, la red es mucho más densa porque no excluimos ningún mensaje entre los investigadores. Al elevar el umbral de dicotomización a 15, la imagen que se obtiene es mucho menos densa porque solo consideramos como lazos válidos a aquellos que superan a los cinco mensajes entre dos nodos:

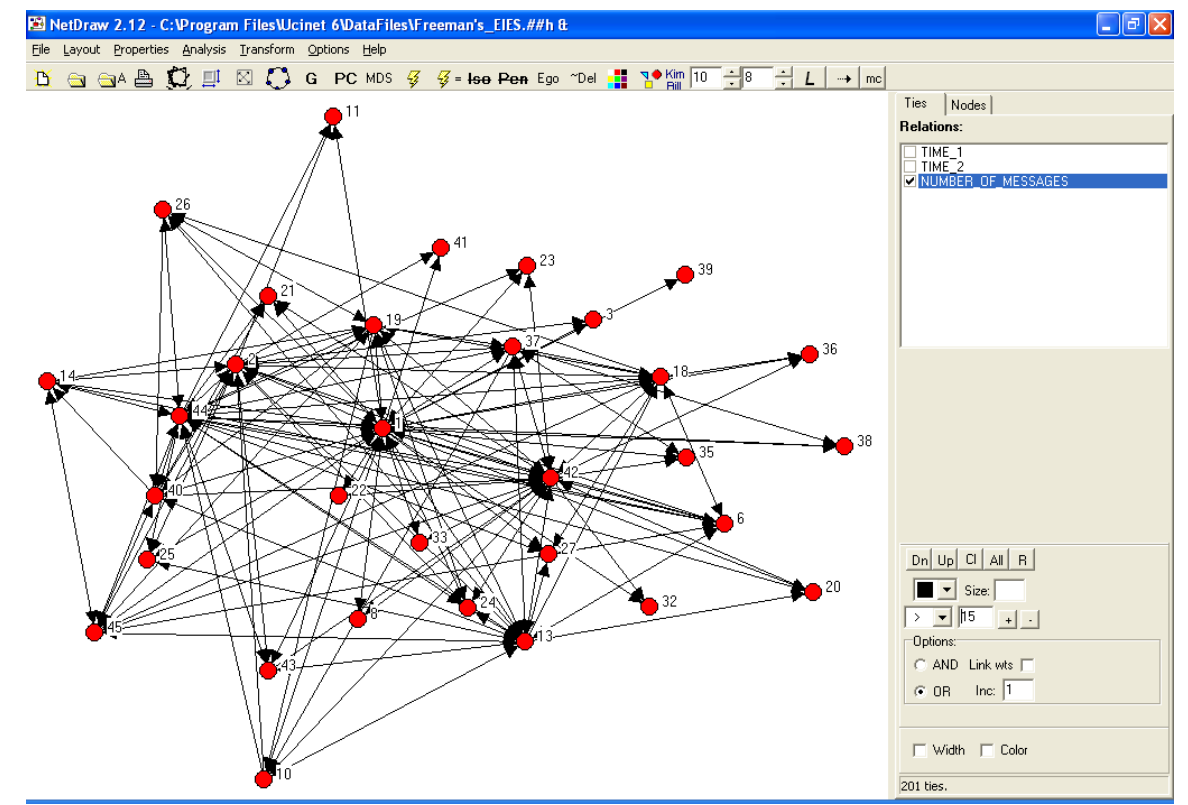

I lustración 3. Redes de intercambio de mensajes de Freeman dicotomizadas a un valor de 15. 
REDES- Revista hispana para el análisis de redes sociales

Vol.14,\#1, Junio 2008

http: // revista-redes. rediris.es

Hay, entonces, una relación procesual asimétrica entre la recolección de datos agregada y desagregada. Lo desagregado se puede agregar, llevar a un nivel de expresión más sintético y luego recorrer el camino inverso, pero lo agregado no se puede desagregar si no contamos con los datos desagregados desde el comienzo.

Una pregunta crucial en cualquier diseño de investigación de redes es, entonces, aquella dirigida a establecer el nivel de agregación correcto o la escala adecuada en la cual quiero obtener mis datos primarios.

\subsubsection{La accesibilidad y colectabilidad de los datos}

Otra cuestión clave que se debe priorizar es la accesibilidad y recolectabilidad inherente a la información empírica de nuestra investigación en curso. Se puede decir que esta accesibilidad es un producto circunstancial de los recursos de los cuales se dispone (no sólo recursos monetarios sino también intelectuales y organizativos) y de la propia ontología de aquello que se desea investigar.

Si se quiere mapear la red de interacciones verbales de un grupo de personas que está hablando prácticamente durante toda la jornada laboral en una empresa, la cantidad de registros que vamos a necesitar de esas interacciones es enorme, y por ende muy importantes los recursos necesarios para completar este mapeo. Tal vez se puedan "muestrear" periódicamente estas interacciones entre 2 nodos cualesquiera y de esta forma reducir los requerimientos humanos y técnicos necesarios para su registro, pero esto implica decisiones de cuidado que pueden desviarnos y hasta alterar los objetivos iniciales de nuestra investigación.

La accesibilidad implica, entonces, una evaluación contextual y empíricamente situada de las posibilidades que tenemos de desarrollar una determinada investigación. En el caso de las redes sociales, la replicabilidad de los procedimientos usados y la altísima estandarización de sus algoritmos de medición y cálculo hace posible algo no muy común en ciencias sociales: la completa reusabilidad de los datos y los análisis ya hechos en función de objetivos investigativos distintos a los originales. Respecto de la utilización de estas ventajas, citaré dos ejemplos puntuales. El primero de ellos es la conocidísima red social de familias florentinas mapeada por los investigadores Breiger R. y Pattison, que fue desarrollada solo tiempo después y sobre la base del monumental trabajo de recolección emprendido por John Padgett durante 2 años y sobre nada menos que un lapso de dos centurias. La abundante y detallada recolección de datos de Padgett y su equipo hicieron posibles las elaboraciones posteriores, pero a su vez 
REDES- Revista hispana para el análisis de redes sociales

Vol.14,\#1, Junio 2008

http: //revista-redes. rediris.es

esta propia investigación fue factible porque ya existían minuciosísimos registros de la vida económica florentina de aquellos años.

En efecto, y como el mismo Padgett señala:

This quantitative-history data set, covering as it does 200 years ( 150 years very thoroughly), is actually unprecedented not just in the field of Florentine studies, but in the field of economic history more generally. [Only the work of Bob Fogel is in the same league.] Needless to say, this data set is possible only because of the extraordinary richness of the original Florentine records, meticulously preserved-itself a testament to the bookkeeping and measurement innovations of the time. The data set's integration of economic networks of partnerships and transactions with temporally parallel political and kinship networks permits a uniquely wide and cross-domain view of the linked transformations in each (Padgett 1999: 3).

Los trabajos basados en las teorías de redes sociales están sujetos, en principio, a las mismas restricciones de fidelidad y consistencia de los datos que cualquier otra investigación, pero además tienen que enfrentar el condicionamiento extra de que raramente el registro de información está diseñado para dar cuenta de la lógica reticular. De los datos colectados por Padgett, solo una parte mostró utilidad para el trazado de una red, pero sin este segmento de información no hubiera sido posible hacer nada ${ }^{8}$. Hay que tener en cuenta que, a menos que transformemos información atributiva en reticular considerando que están vinculados aquellos nodos que tienen similares características (procedimiento metodológicamente legítimo pero epistemológicamente muy pobre si no se apoya con otras inferencias), los datos genuinamente reticulares no pueden ser inferidos si no se cuenta con ellos desde el comienzo.

El segundo caso con que podemos apoyar esta idea de la reusabilidad de la información en una investigación de redes sociales, es nuestra propia aplicación del ARS al estudio de la comunidad tehuelche del valle del Chalía, en la provincia austral argentina del Chubut. Como hemos señalado en oportunidad de nuestro primer relevamiento:

\footnotetext{
${ }^{8}$ La investigación de Padgett nos aporta material para otras discusiones adicionales que por una cuestión de pertinencia no daremos pero que es estimulante señalar. Una de ellas es la de la validez de comparar redes no exactamente coincidentes en el tiempo y considerarlas como representativas del mismo periodo. Para este caso, las relaciones maritales que Padgett tuvo en cuenta, además de ser extraídas de un conjunto mayor de al menos 116 grupos familiares, no coexisten temporalmente con los lazos financieros y políticos tenidos en cuenta. Creo, en definitiva, que esto merecería una discusión pormenorizada sobre la validez de la comparar datos no estrictamente simultáneos (ver Padgett 1999).
} 
REDES- Revista hispana para el análisis de redes sociales

Vol.14,\#1, Junio 2008

http: // revista-redes. rediris.es

(...) utilizando la información recogida por Muñiz en su investigación, nuestro trabajo (Quiroga et al 1999) (...) se propuso objetivos diferentes (...): desarrollamos un abordaje exploratorio y de alcance descriptivo. Intentamos indagar en el potencial analítico que puede tener la teoría de redes y sus metodologías a la hora de representar los vínculos parentales, para poder, posteriormente, profundizar sobre la composición global del sistema de parentesco (Miceli y Guerrero 2002: 3).

Como aquí comentamos, la investigación que dio origen a nuestro trabajo de redes no fue diseñada con estos fines, y creemos que esto es especialmente destacable porque muestra la efectividad de una metodología que, a fin de cuentas, no necesita de más requisitos de factibilidad que una correcta y detallada recolección de información. Partiendo de datos genealógicos y económicos recogidos con otras finalidades, la información reticular capaz de hacer emerger vínculos parentales fue deducida con muy poco esfuerzo y solo mediante procedimientos sencillos de volcado manual, en formato tabular, de los datos ya registrados.

El problema es que no siempre la riqueza y pertinencia de la información disponible está asegurada.

Volviendo al ejemplo de nuestra hipotética red comercial mundial, si nos resultase muy difícil conseguirla, tal vez debamos contentarnos con manejar datos de una porción del mundo o de algunos rubros de ese intercambio pero no de todos. Eso sí, a diferencia de las investigaciones sustentadas en enfoques atributivos y debido al principio de dependencia muestral, no podemos recurrir aquí al muestreo en sentido estricto, lo cual restringe las opciones disponibles al momento de optar por lo que se conoce como "análisis de redes completas"

La accesibilidad de los datos impone, entonces, otra forma de recorte que hay que considerar seriamente en estos casos. Debido a su demanda de exhaustividad, y muy especialmente en el análisis de redes sociales, los procedimientos de

\footnotetext{
${ }^{9}$ Aunque tiene cierto costado controversial, baso esta afirrnación en el comentario de Robert Hanneman en referencia al muestreo de poblaciones: "Debido a que los métodos de redes se centran en las relaciones entre los actores, éstos no pueden ser muestreados independientemente para incluirlos como observaciones. Si un actor llega a ser seleccionado, han de incluirse todos los actores con los cuales éste tiene (o puede tener) relaciones. Como resultado, los enfoques de red intentan estudiar poblaciones totales a través del censo, más que a través de la muestra" (Hanneman: 8) En particular, lo que se pueden muestrear son los tipos de relaciones entre los nodos de una población dada, pero no las relaciones en sí. Esto significa que, si tengo que elegir entre varios conjuntos posibles de vínculos (de parentesco, de afinidad, económicos, de intercambio de información, etc.) puedo escoger uno de ellos y desarrollarlo como red, pero no tengo obligación de tener en cuenta a todos. Sin embargo, lo que no puedo hacer es, una vez elegido un tipo, tener en cuenta solo algunas relaciones y no todas las del tipo elegido, y considerar que el subconjunto de nodos y lazos que elegí es representativo del resto. Esta es la restricción más fuerte que, en ese sentido, tiene el ARS respecto de los enfoques estadísticos tradicionales.
} 
REDES- Revista hispana para el análisis de redes sociales

Vol.14,\#1, Junio 2008

http: // revista-redes. rediris.es

recolección de datos pueden llegar a ser extremadamente costosos y afectar seriamente la capacidad de proseguir con una investigación si no se evalúa su dificultad real a priori.

De tal forma, y como sucede con cualquier investigación no reticular, no vamos a hacer sólo lo que queremos, sino lo que podemos y de acuerdo a nuestros recursos y elecciones explícitas o indirectas.

\subsection{Formalización}

Nunca se formaliza todo lo que se puede formalizar: los sesgos teóricos y metodológicos actúan considerando solo ciertos aspectos y porciones de los datos ya recolectados.

Por otro lado, siempre la problemática que se estudia en el ARS sobrepasa notablemente en interés teórico y en especificidad al simple trazado reticular. Se intenta decir algo sobre la centralidad y el poder, los lazos débiles de una comunidad, la capacidad de difundir una información en un determinado grupo o las relaciones de alianza económica y consanguinidad en un conjunto de familias, pero no sobre la red en sí, que debe ser problematizada para ser interrogada y explorada. En esta segunda instancia, que podemos denominar "formalización", el proceso de filtrado de la información relevante actúa especialmente sobre la masa de información ya colectada y analizada y a partir de objetivos investigativos más finamente delineados. Puede que, en esta hipotética red mundial de intercambio que usamos como ejemplo, interese mucho más determinar cuales son los agrupamientos regionales de colaboración comercial que la centralidad general o la intermediación de los países que participan. Aunque el ARS brinde muchos métodos para abordar la segunda cuestión, y aunque el software de apoyo ponga al alcance de la mano estos cálculos, no va a tener sentido llevarlos a cabo posteriormente porque entran fuera del rango de lo que nos incumbe. Si incluso se apela a un uso exploratorio de esta perspectiva, siempre esa exploración está condicionada por hipótesis específicas o por supuestos más generales que definen el tipo de búsqueda que se hace. En principio el material colectado por una investigación es formalizable total o parcialmente, e incluso las alternativas de formalización no son trivialmente sumativas, porque puede ser que lo que represento de una forma sea incompatible con otras maneras de llevar a cabo este mismo proceso. Las decisiones metodológicas que atañen a estas opciones tienen entonces un altísimo impacto en el resultado final de la investigación y hasta cierto punto son irreversibles porque generan tareas, hipótesis derivadas e inquietudes prácticas y 
REDES- Revista hispana para el análisis de redes sociales

Vol.14,\#1, Junio 2008

http: // revista-redes. rediris.es

teóricas muy distintas a las de otras líneas posibles de indagación. Una vez que se ha elegido profundizar un camino de formalización en detrimento de otros, el efecto de esta decisión condicionará fuertemente el desarrollo posterior de nuestro trabajo, haciendo que la vuelta atrás sea cada vez más difícil en tanto más se haya avanzado por una vía específica y no por otras.

Del mismo modo en que no hay una única estrategia ni un único diseño de investigación que guíe la recolección de datos, la formalización pude hacerse de varias maneras y cada una de ellas tiene distintas consecuencias para nuestros propósitos. La visibilidad de la información, su tratabilidad algorítmica y computacional, y aún su significado formal último pueden verse profundamente modificados por el modo en que inicialmente los representamos.

Partiendo de idénticos datos, no implica lo mismo mapearlos como una matriz de filiación que como una de adyacencia. Las matrices de filiación ponen en primer plano los vínculos entre nodos y no la relación entre los nodos y determinados atributos o propiedades, $\mathrm{y}$, aunque formalmente traducibles una a la otra, ambas representaciones pueden, en el marco de una investigación global, dar origen a visiones e hipótesis no contrapuestas sino muy disímilmente orientadas.

Si queremos representar relaciones entre agentes del mismo tipo, las matrices de adyacencia se ajustarán sin problemas a este propósito, como vemos en la matriz basada en la red de uniones maritales de las Familias Florentinas estudiadas por John Padgett (Breiger \& Pattison 1986).

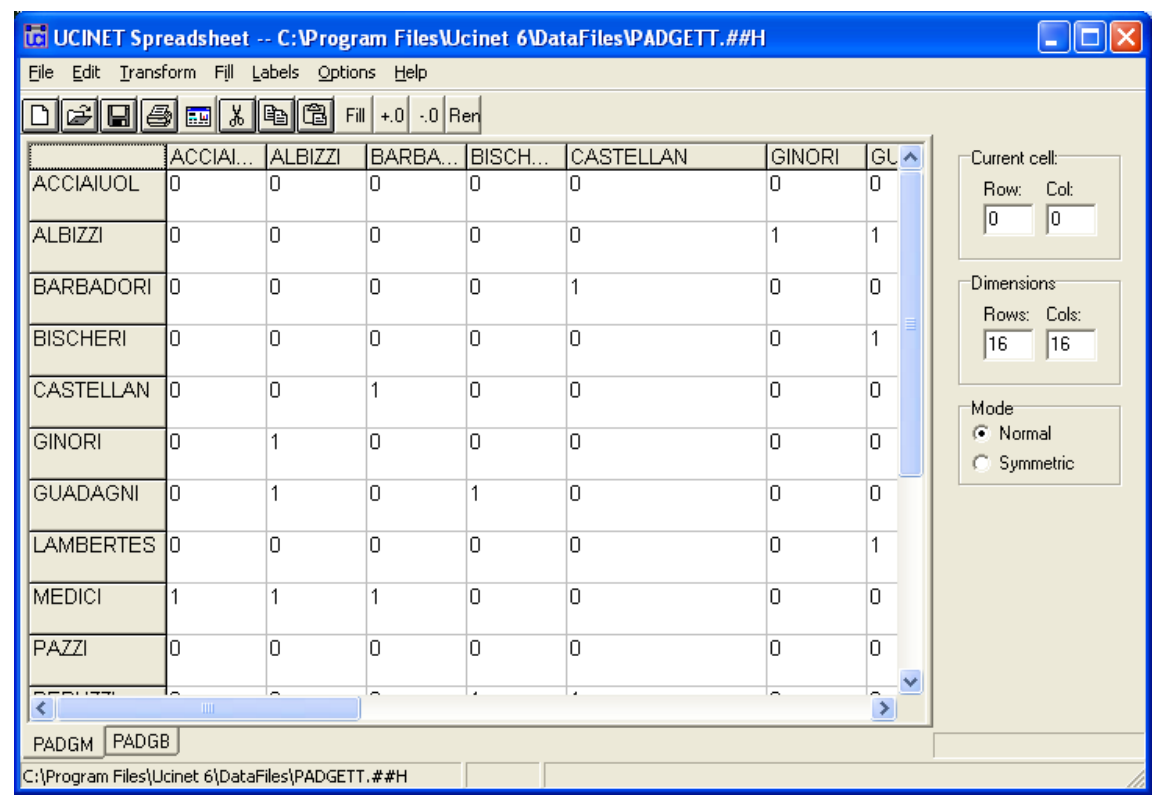

I lustración 4. Matriz adyacente basada en Red de vinculación parental de Familias Florentinas de John Padgett. 
REDES- Revista hispana para el análisis de redes sociales

Vol.14,\#1, Junio 2008

http: // revista-redes. rediris.es

Para la misma red, una matriz de filiación resultaría no solo muy poco informativa, sino inadecuada y difícil de interpretar:

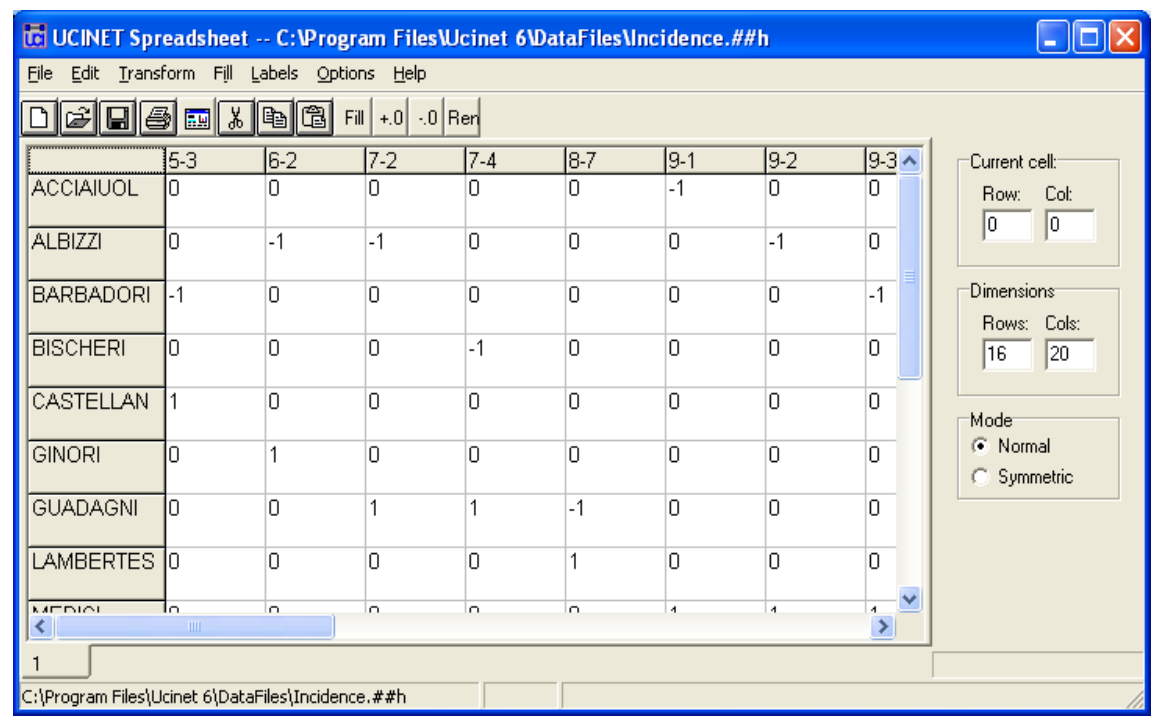

I lustración 5. Matriz de filiación basada en Red de vinculación parental de Familias Florentinas de J ohn Padgett.

En esta representación alternativa de los datos, cada columna representa un vinculo distinto en la matriz (5-3,6-2, etc.) cuyo nombre autodescribe los nodos a los cuales vincula asignándole un número unívoco a cada apellido. De este modo, si la columna se llama 5,3, vinculará a los nodos 3 (Familia Barbadori) y 5 (Familia Castellan). Lo farragoso y molesto de la elección salta a la vista. Si el software UCInet releva 40 relaciones entre los 16 nodos, entonces colocará 40 columnas. La cantidad de columnas de la matriz de adyacencia transformada en matriz de incidencia será igual a la cantidad total de lazos de la matriz. Para redes de alta densidad que tengan esta estructura de vínculos entre nodos del mismo tipo, la interpretación de los datos puede ser torturantemente difícil.

Hasta aquí hablamos de matrices, pero cuando pasamos al terreno de las representaciones visuales el problema emerge con mayor claridad aún. La matriz de adyacencia da lugar a un gráfico visualmente autoexplicativo e intuitivo de los vínculos maritales entre familias florentinas: 
REDES- Revista hispana para el análisis de redes sociales

Vol.14,\#1, Junio 2008

http: // revista-redes. rediris.es

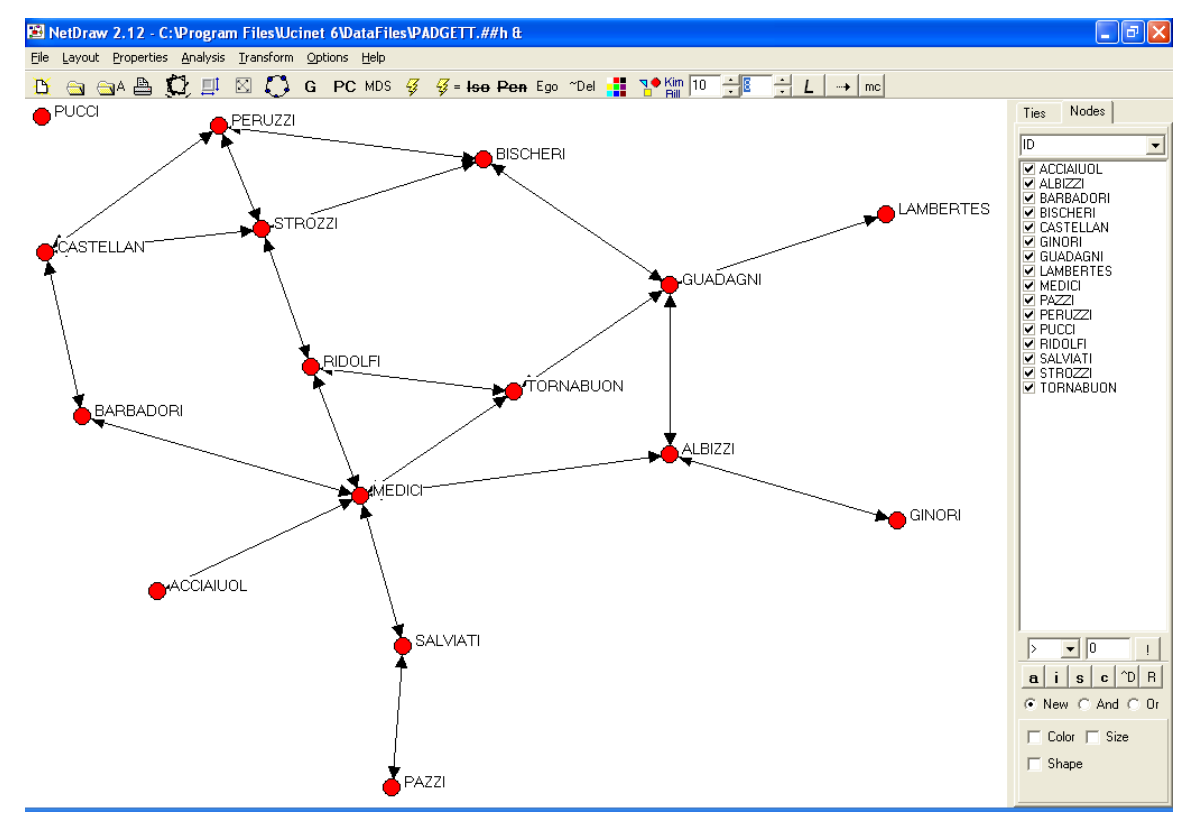

I lustración 6. Gráfico en software NetDraw de Red de vinculación parental de Familias Florentinas de John Padgett partiendo de una matriz de adyacencia.

La matriz de filiación, en cambio, tiene una legibilidad casi nula, porque, al ser mapeada como red de dos modos (familias y lazos individualizados) se han perdido todos los puntos de referencia para comprenderla en un golpe de vista (Comparar la llustración 5 con la llustración 7).

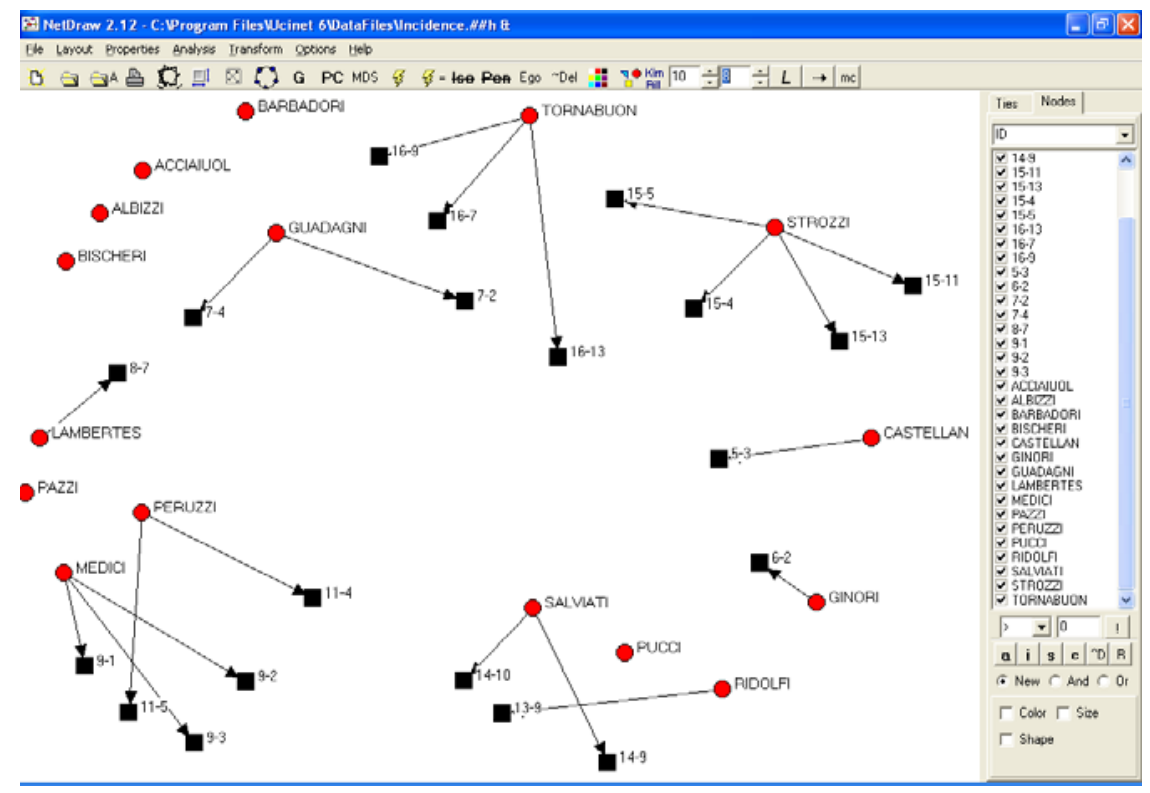

I lustración 7. Gráfico en software NetDraw de Red de vinculación parental de Familias Florentinas de John Padgett partiendo de una matriz de filiación. 
REDES- Revista hispana para el análisis de redes sociales

Vol.14,\#1, Junio 2008

http: // revista-redes. rediris.es

Sin embargo, este no es el único problema y ni siquiera el más relevante que surge al tratar los datos de esta forma. Una matriz de filiación aplicada a esta información resulta completamente ininteligible al momento de hacer los cálculos más elementales. No es solo una visualización inconveniente lo que tendríamos, sino un problema mucho más severo de intratabilidad formal de los datos. Al lidiar con una matriz de dos modos, no sería posible, por ejemplo, ejecutar ninguno de los cálculos de centralidad que si serían factibles en la matriz de adyacencia.

En resumidas cuentas, es importante que nos quede en claro que las estrategias de formalización no implican solo una manera distinta de ver los mismos datos, sino un conjunto de pautas que habilitan algunos caminos de análisis y dificultan $u$ obstruyen definitivamente otros.

\subsection{Análisis y Cálculo}

Nunca se calcula o se analiza todo lo calculable o analizable: Las preguntas e hipótesis, el repertorio de métodos existentes y aún las configuraciones de datos afectan la utilidad de los cálculos disponibles

Una vez que hemos formalizado nuestros datos, que contamos con su representación formal como de red o de matriz, solo hemos comenzado a recorrer un camino que no ofrece menos complejidades en lo sucesivo. Hay un tercer tipo de elección metodológica, la de los procedimientos de cálculo y análisis, que prioriza solo determinados aspectos de lo que se ha formalizado y que no tiene en cuenta a otros. Respecto de los mismos datos no es lo mismo utilizar, por ejemplo, procedimientos de cálculo basados en la idea de Cliqué que hacerlos utilizando el enfoque de $\mathrm{N}$-Cliqué. Como sabemos, el cálculo de Cliqué remite a

(...) un subconjunto de una red en el cual los actores están más cercana y fuertemente conectados mutuamente, que lo que lo están respecto al resto de los integrantes de la red (Hanneman, Cap. VII: 8).

Pero el de $\mathrm{N}$-Cliqué, en cambio, implica una mayor flexibilidad en la consideración de un subgrupo significativo, ya que:

Para muchos propósitos la definición estricta (subgrupo máximo completamente conectado) puede resultar demasiado fuerte. Requiere que todo miembro de un subgrupo tenga un lazo directo con todos y cada uno de los otros miembros. Se pueden pensar casos de cliqués en los que al menos algunos de sus miembros no estén conectados tan cercana ni fuertemente.

Una alternativa es definir a un actor como miembro de un cliqué si está conectado con todos los otros miembros del grupo a una distancia mayor que uno. Usualmente, se usa la distancia de trayecto de dos. Esto es equivalente 
REDES- Revista hispana para el análisis de redes sociales

Vol.14,\#1, Junio 2008

http: //revista-redes. rediris.es

a ser amigo de un amigo. Esta forma se denomina $\mathrm{N}$-cliqué, en la que $\mathrm{N}$ corresponde a la longitud de la trayectoria permitida para hacer una conexión con todos los otros miembros (Hanneman, Cap. VII: 8).

Aplicando ambas medidas a la red de familias florentinas de Padgett, en el primer caso los resultados, como apreciamos en la Ilustración 8, mostrarán una cantidad mucho menor de agrupamientos debido a la naturaleza mucho más restrictiva del concepto de Cliqué que el de $\mathrm{N}$-Cliqué.

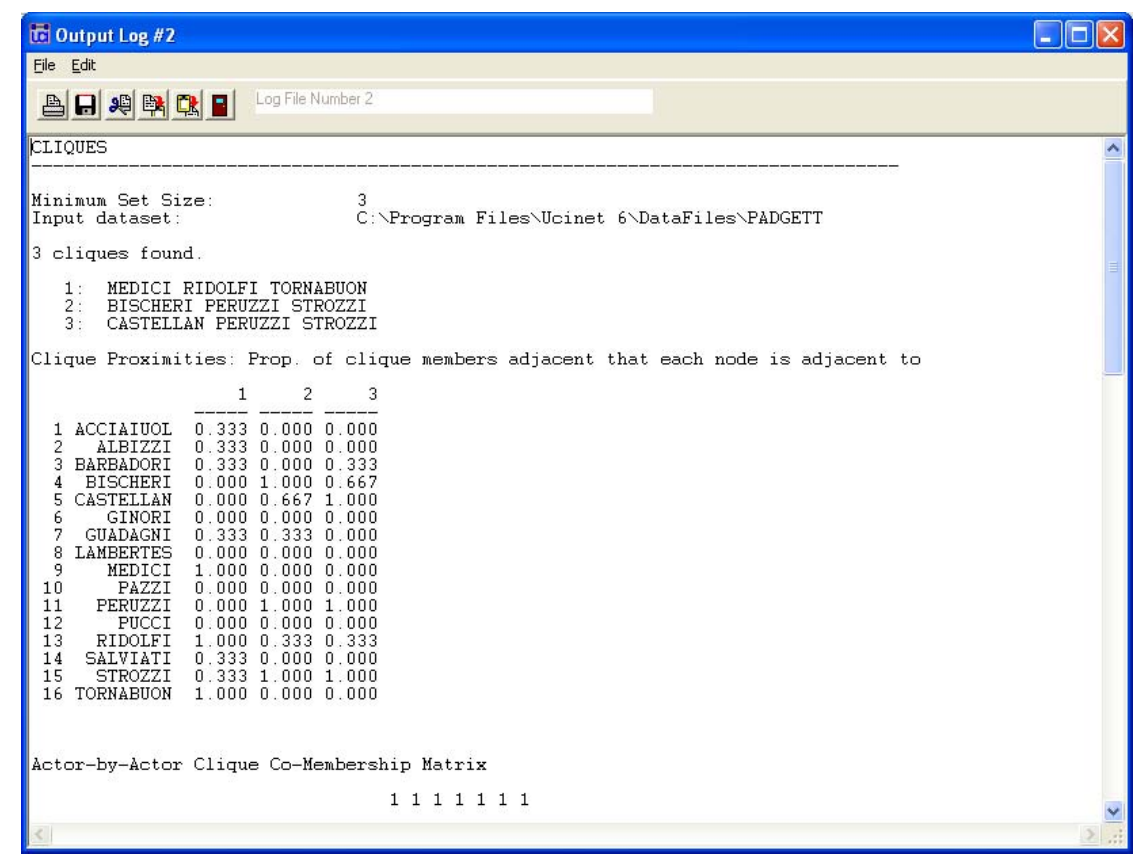

I lustración 8. Archivo de salida en software NetDraw de Red de vinculación parental de Familias Florentinas de John Padgett en base al análisis de Cliqués.

Aquí emergen solo 3 conglomerados, lo cual divide a la red en una cantidad de componentes manejable e interpretable analíticamente.

En el segundo caso, como apreciamos en la llustración 9, obtendremos una cantidad mucho mayor de clusters debido a la regla más laxa que hace que sea tolerable que dentro de un cliqué no todos estén relacionados con todos: 
REDES- Revista hispana para el análisis de redes sociales

Vol.14,\#1, Junio 2008

http: // revista-redes. rediris.es

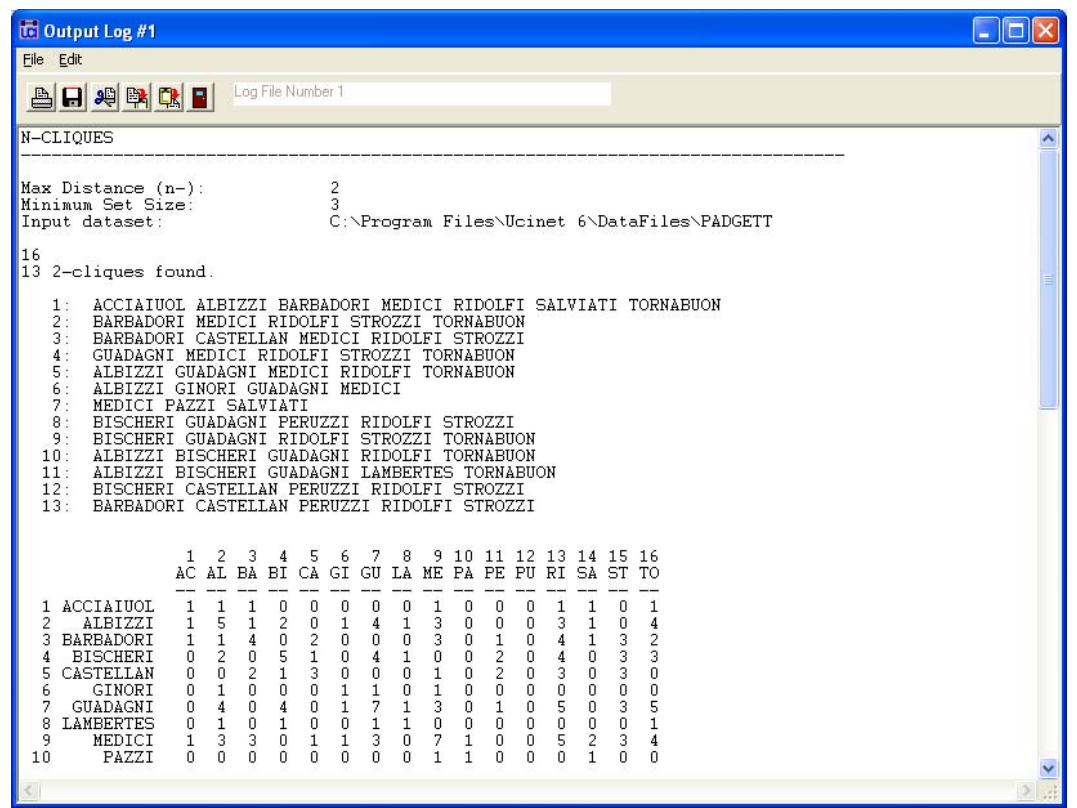

I lustración 9. Archivo de salida en software NetDraw de Red de vinculación parental de Familias Florentinas de John Padgett en base al análisis de N-Cliqués.

Aquí, en cambio, emergen 13 conglomerados, lo cual divide a la red total en muchos más componentes cuyas propiedades, correlativamente, es también más difícil cotejar en un análisis global.

Del mismo modo, los enfoques de Clan y N-Clan, o de K-Plex o K-Núcleo, son capaces de ofrecer diferentes versiones de la misma red analizada en torno al concepto de agrupamiento. ¿Cuál de los enfoques es el correcto? ¿Cuál es más veraz o representativo de los datos que los otros? Un poco de reflexión nos hará percatarnos de que no hay respuesta simple y mucho menos unívoca a esta pregunta. Todo depende de la naturaleza de los interrogantes y de los datos que estemos abordando.

¿Significa esto que no tenemos reglas que determinen globalmente que enfoques son más convenientes que otros en ARS? ¿La utilidad de los enfoques y cálculos es completamente dependiente de la arbitrariedad del investigador?

Aquí la cosa se pone apasionante porque lo que parece un problema y una solución casi obvia tiene consecuencias epistemológicas muy importantes. Si el ARS, presentado como herramienta multipropósito, ofrece cálculos y procedimientos de inferencia diferencialmente útiles frente a determinadas configuraciones de datos, significa que su capacidad de adecuación depende, en definitiva, de detectar qué algoritmo o medida es más acorde a determinada topología de la información que se analiza. 
REDES- Revista hispana para el análisis de redes sociales

Vol.14,\#1, Junio 2008

http: // revista-redes. rediris.es

Los ejemplos para apoyar esta afirmación pueden multiplicarse al infinito. Si tenemos una red muy densamente conectada, como vemos en la Ilustración 10, el análisis de componentes y puntos de corte no tendrá sentido porque será imposible dividir la red en componentes significativos al suprimir solo algunos lazos.

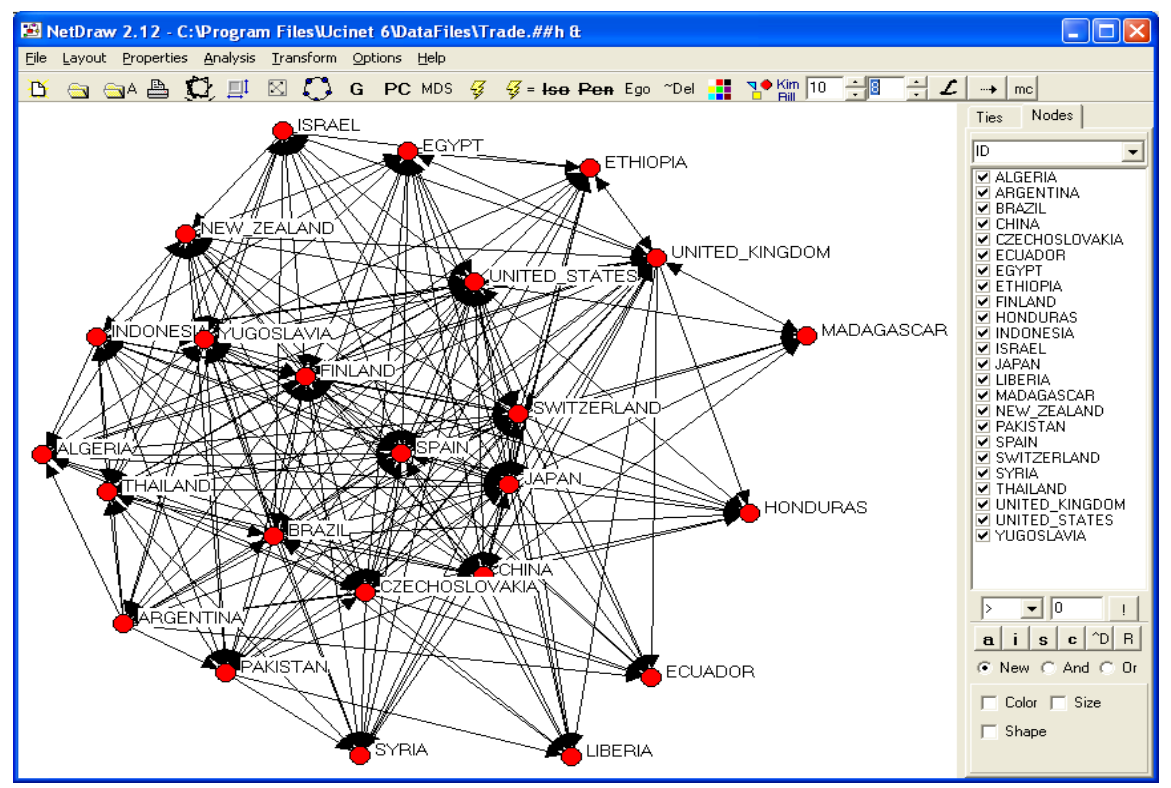

I lustración 10. Gráfico en software NetDraw de Red "Countries Trade Data" mapeada por Smith y White en 1988.

Si por el contrario ella está escasamente conectada y pocos nodos mantienen unidas sus distintas regiones, como en la Ilustración 11, entonces el abordaje de los puntos de corte nos dirá bastante sobre aquellos nodos que cumplen un papel central en la cohesión del conjunto, y podremos imaginar comportamientos y propiedades específicas en función de posibles modificaciones de estos lazos vitales. 
REDES- Revista hispana para el análisis de redes sociales

Vol.14,\#1, Junio 2008

http: // revista-redes. rediris.es

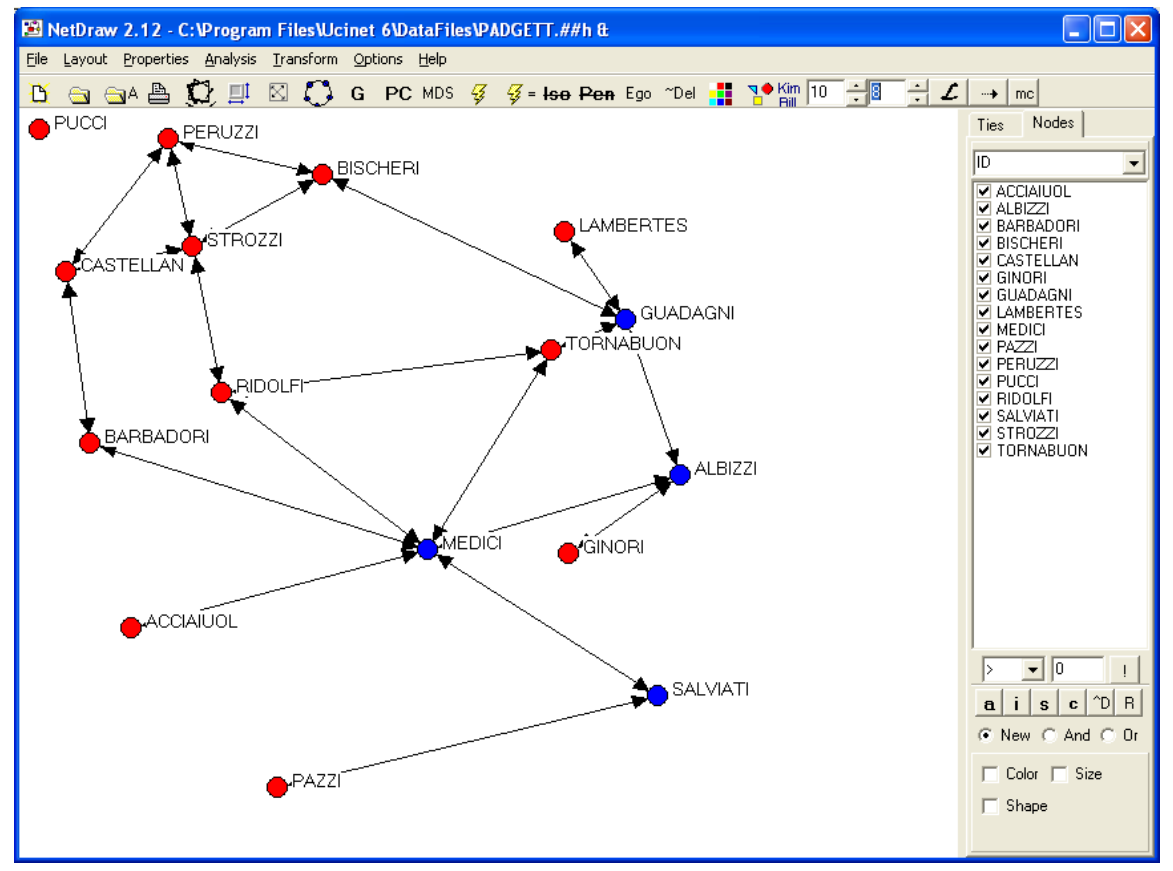

I lustración 11. Gráfico en software NetDraw de Red de vinculación parental de Familias Florentinas de John Padgett aplicando análisis de componentes y puntos de corte.

Como podemos ver, y a diferencia del gráfico anterior, la eliminación de algunos nodos reconfigura drásticamente en esta red de maneras distintas a la original, alterando la forma de recorrerla y aumentando la cantidad de subgrafos dentro de la red.

En definitiva, un costado poco pensado del proceso que analizamos parece salir a la luz de este tipo de comprobaciones. No es solo el investigador el que determina que es interesante o no de un determinado orden de fenómenos, sino que la naturaleza de los datos, convenientemente interrogada, también contribuye a priorizar aquellos enfoques que resultarán productivos en detrimento de otros tal vez menos interesantes.

En general, se puede decir que aquellos enfoques útiles para un determinado conjunto de datos son los que permiten, por un lado, descubrir cortes o subcategorías al interior de ellos, y, por el otro, ligar a estos cortes causal o al menos descriptivamente con fenómenos o discontinuidades de cierta relevancia investigativa. Siendo honestos, no se plantea aquí algo ni remotamente innovador. Si como historiadores intentamos investigar los procesos de revolución social, no sería útil centrarnos por ejemplo en lo que ocurrió en los comienzos de la Edad Media. La realidad no es una tábula rasa que se pueda cortar a piacere obteniendo resultados parecidos en todos los casos. Aunque no se plantee a menudo como una cuestión problemática, lo mismo sucede con el ARS. Algunas familias de indicadores 
REDES- Revista hispana para el análisis de redes sociales

Vol.14,\#1, Junio 2008

http: // revista-redes. rediris.es

y medidas están diseñadas para dar cuenta mucho más específicamente de algunas configuraciones de datos que de otras, y como investigadores tenemos que darnos cuenta de cuando un enfoque deja de ser útil para estudiar determinada información reticular.

\section{Interpretación: siempre se interpretan los indicadores y cálculos de acuerdo a las preguntas e hipótesis de investigación}

Una cuestión que no debemos pasar por alto es que no hay una única forma de interpretar los cálculos que se han hecho en el contexto de una investigación de ARS. Del mismo modo en que podría ser no pertinente aplicar determinados cálculos a determinadas configuraciones de datos, también podría ser no conveniente desplegar interpretaciones desviadas o analíticamente insuficientes como corolario de determinados procesos de investigación.

Es en la etapa de interpretación en donde las preguntas e hipótesis encuentran sus respuestas más afinadas y en donde realmente corroboramos no solo la productividad de nuestro diseño de investigación, sino la contrastabilidad verdadera de lo que hempelianamente podemos llamar sus "implicancias observacionales". Creemos que el tema no es trivial porque el Análisis de Redes Sociales, como cualquier otro andamiaje teórico-metodológico, no puede prescindir de la consideración de su aparato de validación como dispositivo finalmente destinado a probar hipótesis.

Ahora bien ¿Cómo se interpretan en general los datos en el ARS? Creo que hay formas más conservadoras y seguras de hacerlo y maneras epistemológicamente más arriesgadas, y cada una de ellas tiene sus ventajas y puntos débiles.

El Análisis de Redes Sociales, al menos como se lo conoce hoy en día, es una herramienta y una perspectiva conceptual que debe complementarse con una buena dosis de interdisciplinariedad para lograr capacidad explicativa. No es que no ofrezca una muy buena base para hacer inferencias o probar supuestos, pero no debemos confundir los análisis correlacionales o la interpretación rigurosa de indicadores con la elaboración de explicaciones consistentes y abarcativas de los hechos. 
REDES- Revista hispana para el análisis de redes sociales

Vol.14,\#1, Junio 2008

http://revista-redes. rediris.es

A menudo sucede, en los trabajos de ARS, que se confunden hallazgos de correlaciones con verdaderas explicaciones de los hechos, y se produce un salto lógico que infiere, de grados importantes de co-ocurrencia entre variables, la existencia de relaciones causales enteramente hipotéticas.

Es importante en este punto recordar, que, si bien los enfoques correlacionales tienen una fuerte capacidad heurística y también probatoria cuando el cortejo de hipótesis y preguntas de investigación es lo suficientemente específico, de ningún modo son autosuficientes para establecer leyes generales en ámbito alguno.

Se puede postular, en consecuencia de todo esto, que hay dos defectos correlativamente relacionados con las dos formas de interpretación de datos en ARS. Las interpretaciones pobres no superan el estadío correlacional, y las fuertes introducen muchas veces reglas explicativas no sustentadas por los datos que se manejan.

La inclusión, en un diseño de investigación, de leyes que superen analíticamente la suposición de correlaciones, implica un cambio epistemológico y de perspectiva cuya ausencia es fácilmente rastreable en muchas investigaciones en curso. Una gran cantidad de trabajos de ARS parece sujetarse a una implícita validación inductiva que incluso se despliega con índices de ocurrencia casuísticamente muy acotados y que, a lo sumo, califican como generalizaciones al interior de un solo caso. Creo que la etapa de interpretación de los datos necesita imperiosamente de esta instancia teórica para sobrepasar el estadío que supone una heurística simplemente correlacional.

¿Suministra el ARS tal instancia teórica en todos los casos? No siempre con la misma claridad y contundencia. Al rearticularse de diferentes maneras en función de objetivos disciplinares distintos, el Análisis de Redes depende de tradiciones conceptuales e investigativas muy variadas y no siempre queda expuesta y convenientemente validada la trama causal que se avala cada conclusión que se obtiene.

En el siguiente ejemplo, citado de una investigación que juzgo rigurosa y excelentemente estructurada, no deja de quedar visible esta forma de justificar generalizaciones. El trabajo en el que aparecen estas ideas desarrolla un análisis de las relaciones de amistad generadas como producto del programa de intercambio universitario radicado en la Universidad francesa de Lille y llamado ERASMUS, y lo hace a través del uso de uno de los pocos programas de computación dedicado 
REDES- Revista hispana para el análisis de redes sociales

Vol.14,\#1, Junio 2008

http: // revista-redes. rediris.es

exclusivamente al análisis de redes en el tiempo, el software SIENA. En una de las secciones finales y presentando las conclusiones parciales del estudio, se comenta que:

2) Otro resultado particularmente interesante es que las relaciones de amistad con personas de nacionalidad diferente sean más a menudo relaciones recíprocas.

Las relaciones creadas con personas de distintos orígenes, a priori relaciones menos frecuentes, obtienen un estatus de reciprocidad más frecuentemente. Esto parece indicar una valorización particular de estos lazos escasos que poseen un valor añadido ligado a la diferencia de orígenes.

3) Finalmente se ha podido constatar la existencia de diferencias en los modelos nacionales de sociabilidad teniendo como consecuencia comportamientos diferenciados por nacionalidades. De acuerdo con las investigaciones de Fischer (1982b) en que se comparaban estadounidenses y británicos, éstos últimos se muestran menos proclives a crear relaciones de amistad. Por otra parte, los italianos parecen ser preferidos como amigos respecto a otras nacionalidades (Federico 2005, A. De: 174).

Creo que este fragmento ilustra la fuerte dependencia del ARS de ideas que exceden sus herramientas y procesos analíticos de base. Lo que el punto 2 plantea es, simplemente, una correlación estadística de los vínculos entre personas de nacionalidad diferente y la existencia de lazos reciprocitarios entre ellas, pero en ningún momento se formula una regla que ligue ambos comportamientos de manera general y más allá del caso que se analiza. En el párrafo siguiente el carácter inductivo de los razonamientos es aún más claro. Modelos de sociabilidad enteramente distintos se infieren aquí de comportamientos segmentados por nacionalidades, partiendo de constataciones estadísticas muy básicas y sugiriendo configuraciones de rasgos no probadas en el análisis. El hecho de que los italianos sean preferidos como amigos no es explicado, consecuentemente, en función de causas de un orden distinto al de las interacciones o eventos que se mapean.

Por supuesto que no pretendo extraer conclusiones apresuradas de esta incursión ni mucho menos invalidar a la inducción como procedimiento probatorio de hipótesis. Lo que simplemente planteo es la insuficiencia de tal instancia como vertebradora de una interpretación de los datos capaz de generar verdaderas explicaciones. Esto sucede muy a menudo en el ARS porque, a mi modo de ver, su complejo andamiaje metodológico avala una idea exagerada de su autonomía respecto del proceso investigativo general. 
REDES- Revista hispana para el análisis de redes sociales

Vol.14,\#1, J unio 2008

http: // revista-redes. rediris.es

Para profesar con el ejemplo y ver un tanto bíblicamente no solo padeceres ajenos sino también propios, en nuestra propia investigación llevada a cabo en Argentina no hemos sobrepasado exitosamente este estadío inductivo que describimos. Reanalizando los datos sobre nuestra investigación del valle del Chalía, en un trabajo reciente hemos encontrado una importante tendencia a las uniones maritales o de facto con personas que ya habían estado vinculadas anteriormente. A esto lo podemos llamar precariamente "poligamia diacrónica", es factible señalarlo y es posible que, como efectivamente hicimos, sostengamos hipotéticas causas de su aparición y mantenimiento, pero no contamos con un modelo causal que verdaderamente lo explique:

Se nos ocurre, en un contexto meramente especulativo, que la monogamia parece imponer cierto límite al enlace preferencial en las unidades domésticas más conectadas, pero nuestra pauta de relacionamiento es bastante libre y no descontamos que distintos fenómenos como el compadrazgo, los vínculos con la unidad doméstica no basados en lazos de sangre y hasta lo que podemos llamar poligamia diacrónica" o "monogamia sucesiva" (distintas relaciones maritales a lo largo de la misma vida) sean un fuerte inductor conciente o inconciente que potencie la tendencia de los individuos a sumarse a las unidades domésticas que muestren mayor número de lazos de sangre formales o informales con el resto (Miceli et al 2005: 9).

Efectivamente, no podemos pensar en este caso el enlace preferencial (la tendencia selectiva a contraer relaciones con los más relacionados) como un factor explicativo de este tipo de vínculos, porque esto implicaría la falacia de transformar una descripción empírica extendida en una ley de aplicación irrestricta. Podemos asignarle el desempeño de la red a un tipo de dinámica relacional que conocemos y que no describiremos aquí, pero ello no implica que estemos explicando este comportamiento. Al igual que en el caso anterior la tendencia a contraer amistades con determinadas colectividades era sólo corroborada utilizando el ARS, en este la tendencia a establecer pareja es también verificada o descubierta, pero en ningún caso explicada.

Entiéndase, antes que nada, que no se hace un juicio de valor negativo sobre la posibilidad de introducir explicaciones hipotéticas de fenómenos constatables. Lo que se objeta, en todo caso, es la no superación de esta etapa en una gran parte de las investigaciones enmarcadas en esta perspectiva, y el hecho de que, a menudo lo que popperianamente llamaríamos "etapa de descubrimiento", es para ellas el instante de cierre y el horizonte de clausura. 
REDES- Revista hispana para el análisis de redes sociales

Vol.14,\#1, Junio 2008

http: // revista-redes. rediris.es

Obviamente es una idea a discutir y sus alcances son muy variados, pero sospecho que este techo epistemológico tiene que ver, en parte, con el prestigio de un aparato metodológico que parece no necesitar de instancias externas de validación pero que, en realidad, no cuenta con una semántica integrada para interpretar sus procedimientos analíticos.

La interpretación de los cálculos presentes en el ARS en función de hipótesis previas, entonces, es inherentemente problemática, y sus dispositivos están bastante alejados de la simple lectura de indicadores, como parecen sugerir algunas investigaciones. Opino que la validez de estas inferencias, más que estar garantizada por el background analítico y el software de base, debe ser sometida a prueba y examinada mucho más allá de la aparente conclusividad de cada examen de resultados.

\section{Intervenciones en red: no siempre se trata de ampliar las redes preexistentes}

La intervención en una red cualquiera con el propósito de modificarla es otra etapa en donde los problemas de validez de las inferencias juegan un papel incluso más crítico que en las fases anteriores, porque, al menos en la mayoría de los casos, no existe la posibilidad de revertir los efectos de una modificación inadecuada de su estructura.

Además de representar esto una problemática práctica y teórica hay, por supuesto, fuertes connotaciones éticas asociadas a intervenciones erróneas o poco felices en la vida social real.

El ARS cuenta, aún hoy en día, con un prejuicio mayoritariamente positivo originado tal vez en su versión metafórica: mucha gente cree que toda modificación de una red que tienda a aumentar su conectividad, a fortalecer sus lazos, es intrínsecamente benéfica. Desde muchas posiciones democratistas e igualitarias, distintos valores positivos han sido asociados al Análisis de Redes, y de manera general se piensa que sus conclusiones e implementaciones son predominantemente liberadoras en términos sociales. Como sostiene Ana Laura Rivoir:

En las reflexiones sobre la intervención, las redes sociales son consideradas como preexistentes o como formas organizacionales a ser construidas. Se trata, por un lado, de detectar las redes sociales en búsqueda de una mejor intervención y en otros casos de crear este tipo de organizaciones como instrumento de fortalecimiento de la sociedad civil. Networking o trabajar en red es una expresión utilizada en relación a esta propuesta de intervención. 
REDES- Revista hispana para el análisis de redes sociales

Vol.14,\#1, Junio 2008

http: // revista-redes. rediris.es

Estos enfoques se caracterizan por adoptar un sesgo normativo dado que al propio término de red social, se le asigna una connotación positiva y se las asimila a modelos de relacionamiento social. Se le asigna a las redes características como las de su "horizontalidad" lo que implicaría más democracia, "creatividad" en cuanto a la capacidad de adaptación, que facilitan la participación, y la "solidaridad", entre otros. En este sentido, la construcción de las mismas aparece como meta (Rivoir 1999: 6).

Aquí, sin embargo, se puede establecer al menos una división significativa entre los tipos de intervención imaginables en una red. Creo que estas acciones responden a diferentes objetivos y condiciones, y que en todas ellas se resuelven de manera implícita problemas éticos cuya consideración no es simple. En este caso la reflexión sobre la validez del ARS tiene una doble cara interdependiente: hay una validez técnica y una validez ética de las intervenciones. El juicio técnico que concierne a la efectividad, que se priorizó en las otras etapas, no puede dejar aquí de lado las cuestiones morales derivadas de una modificación voluntaria de la realidad social. Como se verá con algún detalle, el ARS en su uso concreto depara los mismos riesgos y problemas que cualquier otra metodología capaz de generar cambios reales en la vida de las personas. Ni su utilización es ideológicamente neutra ni, muchísimo menos, destinada únicamente a generar beneficios en la sociedad. Tampoco consiste básicamente, como desde cierta epistemología ingenua parece predicar, en desarrollar y crear vínculos entre las personas o grupos. Por lo contrario, en muchísimos casos y para bien o mal, es una herramienta identificatoria de aquellos vínculos que resultaría conveniente suprimir para lograr una meta específica.

\subsection{Networking inducido: el uso estratégico del "trabajar en redes"}

En general se hace alusión al Networking como una de las posibilidades de uso de la perspectiva de redes. El "trabajar en redes", como concepto general, conlleva la actividad descentralizada y no planificada de un conjunto de individuos tratando de generar y explotar los lazos de una red (Rivoir 1999). A pesar de que esta es una práctica muy extendida en el mundo empresarial y aún en el académico, no es posible incluirla dentro de las intervenciones que echan mano del ARS como herramienta de análisis. El presupuesto general de esta modalidad es simplemente que el fortalecimiento y la creación de relaciones, sin coordinación central, aumenta las oportunidades de los nodos de obtener recursos, conocimientos o habilidades presentes en otros integrantes.

Si se consultan los sitios especializados en Networking dentro de Internet, no se encontrarán explicaciones sofisticadas de esta operatoria, sino una serie de 
REDES- Revista hispana para el análisis de redes sociales

Vol. 14,\#1, J unio 2008

http: // revista-redes. rediris.es

consejos sobre como presentarse en sociedad y generar la mayor cantidad de contactos posibles:

¿Qué pasaría si no puede asistir a un evento importante de networking? ¿Qué pasaría si quisiera expandir sus actividades de networking pero no tiene el tiempo o la energía para llevarlo a cabo personalmente? ¿Cuán efectivo sería su personal si tiene que asistir en su lugar y representar a la empresa? ¿Saben realmente lo que tienen que decir y preguntar? El Networking es la forma más poderosa de marketing cara a cara. Lo que usted diga puede impactar en forma positiva o negativa en la efectividad del mismo. Su habilidad para contar su historia en veinte segundos o menos es una de las claves más importantes en el éxito de su networking... y hasta un factor igualmente grande en el éxito general de su empresa (ver Krieger).

Estimo que no se pueden esperar, desde esta posición constitutivamente antiteórica, demasiadas reflexiones sujetas a un método o un sistema de diagnóstico que respete la más mínima rigurosidad en la elaboración de estimaciones. Los consejos de los especialistas en Networking no superan las conclusiones de alguien solo fiel a su menos pretencioso sentido común. Simplemente quienes participan de esta perspectiva opinan que:

En los eventos de networking, el objetivo es hacer contacto con la mayor cantidad de gente posible (ver Krieger).

Nótese lo simples que son estas observaciones y definiciones, y no es difícil darse cuenta del escaso bagaje conceptual que se requiere para seguir sus lineamientos no es mayor que la intuición primaria de que, si uno logra muchas relaciones y de buena calidad, es más posible que se alcancen bienes, servicios o conocimientos ligados a esas relaciones.

Creo que, al menos en esto términos, no es exagerado sostener que toda la batería terminológica proveniente del márketing no hace más que reforzar esta intuición casi obvia, y deja a esta perspectiva bien distante de cualquier aplicación técnica del ARS.

\subsection{Networking espontáneo: no se puede evitar estar en red}

Además de un Networking inducido o facilitado por una infraestructura específica y dirigido a una actividad en particular, es posible pensar en el networking como una actividad espontánea e inherentemente descentralizada. Por un lado, todos los días interactuamos tratando de generar nexos, modificando nuestro entorno y creando y alterando relaciones. No lo hacemos con una finalidad homogénea ni con una teoría detrás que nos guíe, pero podríamos asumir que la sociabilidad humana implica la reingeniería permanente de los vínculos de las personas entre sí. 
REDES- Revista hispana para el análisis de redes sociales

Vol.14,\#1, Junio 2008

http://revista-redes. rediris.es

Aunque no exista una visión estratégica de estos cambios, aunque ellos no se evalúen con el andamiaje técnico del análisis de redes, podemos afirmar que la intervención reticular continua es inherente a la vida en sociedad. ${ }^{10}$

También podríamos hablar de un Networking espontáneo circunstancial, que es aquel que se produce en situaciones capaces de facilitar transmisiones masivas de mensajes, modificaciones globales de vínculos o cambios muy significativos de la estructura general de un momento para otro. No habría aquí un cambio gradual de las relaciones, sino una transición dramática de un tipo de configuración a otra.

Los dramáticos eventos que precedieron y sucedieron a la derrota del presidente Aznar en España en las elecciones ante Rodríguez Zapatero el 14 y 15 de Marzo de 2004, con los cuales se gestaron manifestaciones de masivas ante la misma sede del entonces oficialista Partido Popular español en el curso de horas, son un ejemplo muy claro de este tipo de intervenciones. En el curso de ellas, una gran cantidad de gente se vio involucrada en un intercambio de mensajes de texto capaz de producir efectos sociales de alto impacto en muy poco tiempo. Ante el intento manipulatorio del gobierno español de entonces, que incluso utilizó a una gran parte de la prensa para culpar a la ETA de los atentados del 11 de Marzo del mismo año en la Terminal ferroviaria de Atocha, en los suburbios de Madrid, un nuevo tipo de percepción de los hechos emergió a la luz y se difundió utilizando el poder invisible de las redes. Ante las crecientes sospechas de que culpando al terrorismo vasco se estaba desviando la atención para no admitir la responsabilidad gubernamental por la posible represalia de Al-Qaeda contra la intervención militar española en Irak, un enorme y sorprendente número de personas fue capaz de autoconvocarse utilizando la tecnología SMS y con la simple consigna "A las 6, al PP, por la verdad" (ver http://www. pagina12.com.ar/diario/elmundo/4-326522004-03-14.html). Creo que la dimensión profética de estas acciones puede advertirse cuando se visualizan estos hechos como producto de una confrontación entre dos estrategias opuestas de difusión informativa. En un bando podríamos ubicar a la clásica acción mediática de orden centralizado, y en el otro a la acción descentralizada y sustentada en una tecnología relativamente nueva y poco consolidada como el mensaje de texto.

\footnotetext{
${ }^{10}$ Así como Aristóteles consideraba que los humanos éramos antes que nada "animales políticos", creo que podría decirse que también somos, ontológicamente, animales reticulares.
} 
REDES- Revista hispana para el análisis de redes sociales

Vol.14,\#1, Junio 2008

http://revista-redes. rediris.es

Por otro lado, y más allá de estos acontecimientos extraordinarios o poco comunes, los cambios tecnológicos no dejan de afectar la forma en que nos relacionamos día a día. No es aventurado afirmar que la aparición del e-mail ha aumentado exponencialmente la capacidad de transmisión de contenidos en la modalidad tradicional o de "broadcasting" (uno a todos). Lo que el mail introduce, a diferencia del teléfono de línea, es la posibilidad de potenciar estos mecanismos de difusión ultrarrápida de la información a un costo bajísimo y con una efectividad casi ideal. La misma tendencia está siendo acompañada por la evolución de la telefonía celular a través del ya mencionado SMS. El networking a gran escala progresivamente modifica nuestras posibilidades de interacción con personas conocidas y anónimas, extendiendo increíblemente el tamaño de nuestra red potencial de contactos.

\subsection{Investigación / Programación de Tomás Villasante: la construcción de redes de manera programada}

Dentro de las iniciativas que hacen un uso sistemático del análisis de redes sociales (lo que llamamos Análisis Estructural de Redes Sociales) Rivoir hace referencia a los planteos de Tomás Villasante, quien según esta autora:

(...) ha desarrollado una metodología de redes sociales en la que estas son consideradas parte de la realidad social a estudiar y con la que el cientista social interactúa en el proceso de investigación-acción. Sus investigaciones se centran en temas de participación ciudadana y movimientos sociales dándole particular importancia a las dimensiones cultural e identitaria. Hay que destacar que autor parte, y lo explícita, de un compromiso y involucramiento con el cambio social y la mejora en la calidad de vida de la población.

A su entender es insuficiente para un análisis integral de una realidad dada, tratar solamente las redes sociales, sostiene que es necesario analizar también lo que llama los bloques sociales y los conjuntos de acción. Destaca el uso de técnicas cualitativas, en particular para el análisis de las motivaciones y los discursos de los actores, pero considera importante la combinación con las técnicas cuantitativas (Rivoir 1999: 10).

Aunque Rivoir tal vez no lo aclare, se puede decir que esta metodología integrada de intervención participa de los mismos supuestos de normatividad positiva que la metodología del ARS inspira en el público no experto. Se supone que luego de transcurridas ciertas etapas de relevamiento de la información, las personas que integran una red serán capaces de diagnosticar, con ayuda de especialistas, sus propias necesidades de reestructuración de la red (Rivoir 1999: 11). 
REDES- Revista hispana para el análisis de redes sociales

Vol.14,\#1, Junio 2008

http: // revista-redes. rediris.es

Sin embargo he detectado, en la panorámica dada por esta autora, una omisión clave, ya que no se tienen en cuenta las intervenciones de una red de carácter totalmente centralizada y con objetivos no necesariamente autopotenciadores como los señalados. Como se verá a continuación, el conocimiento del ARS es útil no solo para crear o potenciar vínculos, sino también para destruirlos o limitarlos.

\subsection{Intervención privada o estatal en redes: el ARS también sirve para destruir vínculos}

Desgraciadamente, el ARS se ha transformado en una herramienta demasiado poderosa como para quedar confinada exclusivamente al terreno de las buenas intenciones. Además de la problemática moral inherente a la modificación de cualquier realidad social que no salga como la planeamos, no hay que perder de vista los objetivos de aquellos organismos e instituciones que directamente echan mano de esta perspectiva con propósitos manipulatorios y muy por fuera de cualquier dinámica consultiva.

No es una novedad destacar que los eventos ocurridos el 11 de Septiembre de 2001 en el World Trade Center de Nueva York alteraron definitivamente el mapa geopolítico del mundo y generaron un reposicionamiento de las agencias de seguridad frente a la problemática de los atentados producidos por grupos radicales islámicos, en lo que genéricamente la administración del presidente George W. Bush ha denominado, en el plano internacional, "Guerra contra el terrorismo".

Algunas aplicaciones del Análisis de Redes han tenido un rol central en las políticas de control y monitoreo de la actividad de grupos sospechados de estas actividades, transformándose en la herramienta teórica y en la metodología predilecta para rastrear el curso de redes de información y flujo de personas. Además de no ser participativo en el sentido de que no se busca que los integrantes de las redes analizadas hagan algo en su propio beneficio, este tipo de enfoque no es pasivo ni neutral frente a su objeto de estudio y análisis. En el caso del terrorismo, lo que se busca es que estas redes dejen de funcionar como lo están haciendo, y el medio elegido para lograr este objetivo puede incluir desde la captura de los miembros de la organización hasta su eliminación física. El estudio y la desarticulación de redes criminales o de corrupción, o aún de redes de actividad política, de contrabando o de acciones sospechosas a ojos gubernamentales, pone en primer plano el uso del ARS como herramienta técnica capaz de brindar un sólido conocimiento de los fenómenos que se analizan. 
REDES- Revista hispana para el análisis de redes sociales

Vol.14,\#1, Junio 2008

http: // revista-redes. rediris.es

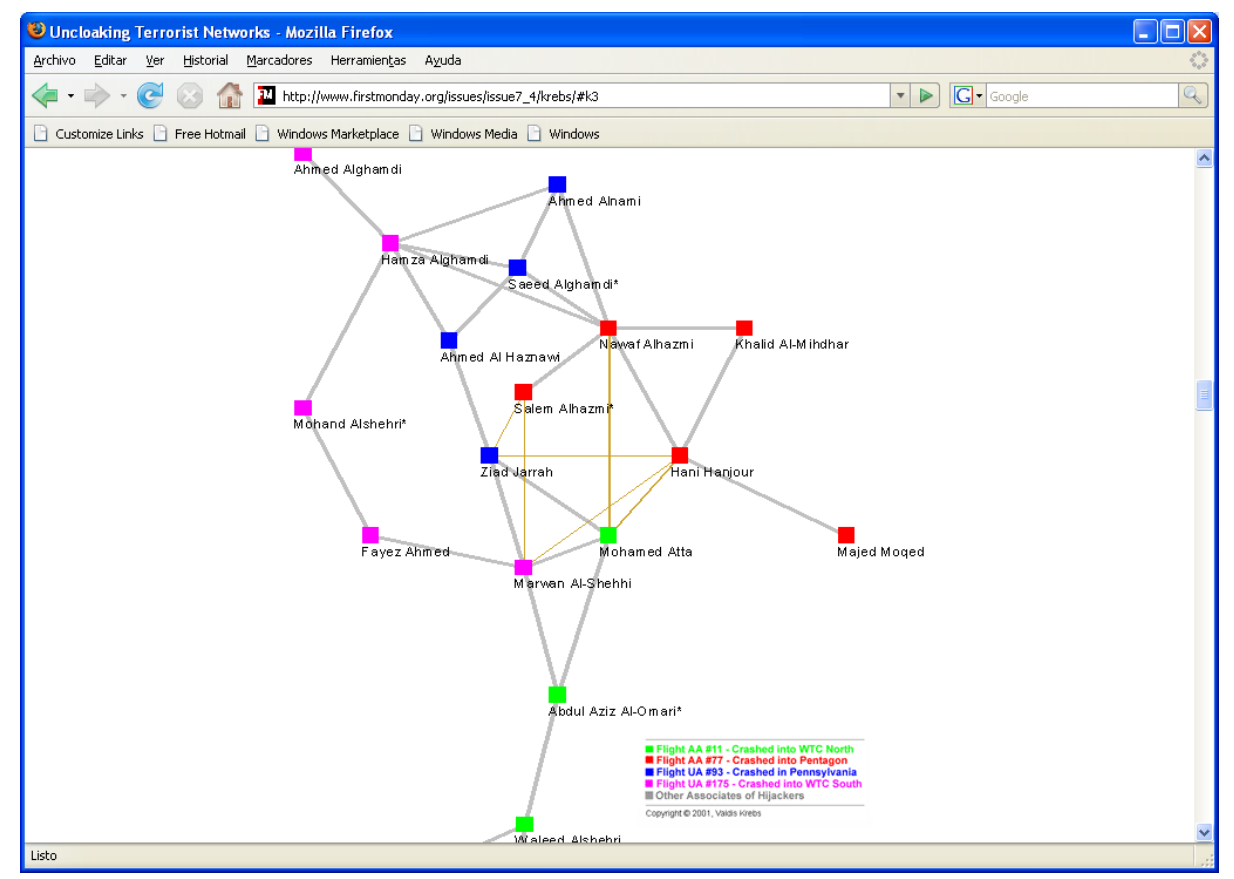

I lustración 12. Mapeo de red de terroristas que intervinieron en los atentados del 11/09/01.

La red que mostramos arriba fue confeccionada siguiendo los lineamientos técnicos del Análisis de redes y reveló gran parte de la trama de relaciones capaz de provocar los eventos del 11 de Septiembre del 2001. No se trata, por supuesto, de que únicamente nos proclamemos a favor o en contra de estos usos, porque ellos se impondrán inevitablemente para los objetivos que comentamos. Es necesario que se tome conciencia del enorme poder que este conocimiento conlleva y de que no podemos librarnos de los dilemas morales que estas opciones habilitan. Quizás la verdadera irrupción de un estado orwelliano y desprovisto de límites en sus accionar no esté precedida, como se pregona, de un conocimiento invasivo de la intimidad de las personas, sino de la investigación obsesiva y detallada de cómo ellas se vinculan entre sí y con los eventos e instituciones de las cuales participan en cada instante de sus vidas. Existe la posibilidad, que considero temible desde todo punto de vista, de que la verdadera capacidad de control de los estados y gobiernos se ejerza echando mano mucho más del conocimiento reticular que del privado. Creo que es interesante pensar que el poder, en su concepción clásica, ha tratado de actuar, la mayoría de las veces, controlando y clasificando a las personas a las personas en virtud de los atributos que las distinguen (ideología política, pertenencia étnica, etc.) No es que la perspectiva reticular no haya estado presente en las dictaduras y aún en los gobiernos no totalitarios (la organización estatal o paraestatal de la tortura para incentivar cadenas de delaciones es un claro 
REDES- Revista hispana para el análisis de redes sociales

Vol.14,\#1, Junio 2008

http: // revista-redes. rediris.es

ejemplo del uso intuitivo de la noción de redes de información), pero indudablemente ingresamos en una era en la que la tecnología se va a constituir en una aliado indispensable para el mapeo rápido y confiable de las redes de relaciones que circunscriben el accionar de las personas.

En particular creo que será necesario incorporar a la noción de "privacidad" la información de las redes en las que se desempeñan las personas, aún aquellas redes en las que no esté en juego, al menos de manera evidente, ninguna información de carácter público.

Otro campo de aplicación del ARS que también merece atención desde las esferas estatales, paraestatales y privadas, son las redes epidemiológicas o de difusión de enfermedades. ¿Cómo se aplica el Análisis de Redes en estos casos? Por supuesto que la respuesta no es unívoca ni fácil de desplegar sin detalles, pero un objetivo importante de estas investigaciones es detectar de qué modo se difunde una enfermedad en una población, para luego actuar tratando de limitar lo más posible su rango de expansión. La factibilidad de lograr este objetivo depende no sólo de las características de los grupos de riesgo, de su nivel de exposición a los agentes patógenos y de la letalidad de estos últimos, sino también de la forma precisa de la red en la cual las enfermedades se difunden (Ver http://www.caps.ucsf.edu/espanol/hojas/pdf/redesFS.pdf).

Más que en ninguna otra área, las formas de intervención están catalogadas con bastante precisión por quienes, desde el trabajo sanitario, utilizan el análisis de Redes. Para el caso del HIV las directivas son bien específicas: por un lado hay que identificar a quienes actúan como transmisores principales de la enfermedad, y por el otro hay que fragmentar planificadamente la red en la que la epidemia se produce.

En la siguiente matriz se muestran, a manera de sinopsis, los diferentes tipos de intervenciones que han sido descriptas hasta ahora: 
REDES- Revista hispana para el análisis de redes sociales

Vol.14,\#1, Junio 2008

http://revista-redes. rediris.es

\begin{tabular}{|c|c|c|c|c|c|c|}
\hline $\begin{array}{c}\text { Tipos de intervención } \\
\text { en Red }\end{array}$ & $\begin{array}{c}\text { Con } \\
\text { Planificación } \\
\text { Central }\end{array}$ & $\begin{array}{c}\text { Sin } \\
\begin{array}{c}\text { Planificación } \\
\text { Central }\end{array}\end{array}$ & $\begin{array}{c}\text { No } \\
\text { Participat. }\end{array}$ & Participativa & Objetivo & $\begin{array}{c}\text { Uso } \\
\text { técnico } \\
\text { del ARS }\end{array}$ \\
\hline Networking inducido & & $x$ & & $x$ & $\begin{array}{l}\text { Creación } \\
\text { de } \\
\text { Lazos }\end{array}$ & NO \\
\hline Networking “Natural” & & $x$ & & $x$ & $\begin{array}{c}\text { Creación } \\
\text { de } \\
\text { Lazos }\end{array}$ & NO \\
\hline $\begin{array}{l}\text { Networking } \\
\text { “repentino" (Difusión } \\
\text { instantánea de ideas } \\
\text { o información) }\end{array}$ & & $x$ & & $x$ & $\begin{array}{l}\text { Creación } \\
\text { de } \\
\text { Lazos }\end{array}$ & NO \\
\hline $\begin{array}{l}\text {-I nvestigación / } \\
\text { Programación de } \\
\text { Villasante } \\
\text { Programas } \\
\text { descentralizados de } \\
\text { intervención en red }\end{array}$ & $x$ & & & $\mathrm{x}$ & $\begin{array}{l}\text { Creación } \\
\text { de } \\
\text { Lazos }\end{array}$ & SI \\
\hline $\begin{array}{l}\text {-Control Estatal o } \\
\text { privado } \\
\text {-Seguridad } \\
\text { (Terrorismo, crimen) } \\
\text {-Epidemiología }\end{array}$ & $x$ & & $x$ & $x$ & $\begin{array}{l}\text { Destrucció } \\
\text { n física de } \\
\text { la red } \\
\text { Fragmenta } \\
\text { ción de la } \\
\text { red }\end{array}$ & SI \\
\hline
\end{tabular}

Tabla 2. Tipos de Intervención en Red.

Desde ya que no es esta una taxonomía exhaustiva de los posibles campos de acción del ARS. Quedan sin comentar intervenciones hechas en redes empresariales, de productores, las redes de conocimientos, etc. Prácticamente toda actividad humana sujeta a interacciones regulares entre personas o entidades es susceptible de abordarse de esta forma, y por ello es imposible abarcar todos sus usos posibles. En particular, hay un terreno gris en el que el análisis de redes tal vez lleva implícita cierta acción no conciente sobre los lazos que se analizan. En efecto ¿No estamos alterando de alguna manera una red por el solo hecho de conocer su conformación? Esta pregunta es válida, pero escapa completamente a los fines de este artículo.

Por otro lado, todas las hipótesis de intervención propias de esta etapa se basan en la capacidad predictiva basada en el desempeño de redes anteriores análogas o de la misma red actual en otros momentos. Como se vio hasta aquí, no en todos los casos se interviene de manera centralizada y no siempre se tiende a construir vínculos o fortalecerlos. Ambas certezas escapan de los lugares comunes que externamente se le asignan al ARS, pero, como investigadores practicantes de esta perspectiva, podríamos decir que este abanico de alternativas no produce mayores inquietudes en nuestra valoración ética profesional. Sin embargo, la irrupción de 
REDES- Revista hispana para el análisis de redes sociales

Vol.14,\#1, Junio 2008

http://revista-redes. rediris.es

los estados nacionales y de las agencias privadas como agentes de estas intervenciones involucra consecuencias demasiado relevantes como para dejarlas de lado. ¿Quién supervisa la validez ética de las acciones sobre una red? ¿En nombre de qué principios se puede obtener conocimiento sobre los vínculos y el comportamiento de un grupo y usarlo estratégicamente a favor de objetivos políticos de otro orden? El estudio del terrorismo aparece como el ejemplo más extremo de uso del ARS con fines muy discutibles, pero la epidemiología y otras áreas aparentemente más aptas para un desempeño "benéfico" tampoco están al margen de estos cuestionamientos. ¿Quién garantiza que la información obtenida no se utilice, en el caso de las enfermedades infecciosas, para fines menos loables que frenar una epidemia? No es fácil responder estas preguntas, pero creo que es necesario tomar conciencia de que su respuesta es de un orden cualitativamente muy distinto al de los obstáculos técnicos y las dificultades explicativas o de validación meramente teórica que encuentra el ARS en la actualidad.

\section{Algunas conclusiones finales}

El recorrido que propuse es sesgado e insuficiente, pero aspiro, al menos, a haber llamado la atención sobre una serie de tópicos que considero centrales en cada etapa del esquema propuesto:

1. Las restricciones y problemas que afectan a la etapa de recolección de datos, entre las cuales la naturaleza emic o etic de los mismos, la definición atributiva o relacional, la accesibilidad y el principio de dependencia muestral son las más importantes. Los datos del ARS deben ser relevados con especial exhaustividad y completitud, lo cual obliga a un diseño de investigación muy preciso y detallado desde el comienzo.

2. Las complejas operaciones involucradas en la formalización de los datos, que pueden generar una representación formal completamente inoperante a los efectos de responder las hipótesis y preguntas de investigación planteadas. Las diferentes formalizaciones no son neutras investigativamente, sino que habilitan algunas vías de análisis y clausuran otras de la misma manera en que lo hacen los supuestos más generales de cada científico social.

Como rasgo característico de esta etapa subrayé la relativa reusabilidad de la información, la cual permite desligar la etapa de recolección al resto de las fases y también torna posibles formalizaciones de datos que originalmente no fueron obtenidos con ese propósito. 
REDES- Revista hispana para el análisis de redes sociales

Vol.14,\#1, Junio 2008

http: // revista-redes. rediris.es

3. Lo problemático de la realización de cálculos y análisis que realmente sirvan a los objetivos de la investigación, principalmente por la estrecha y selectiva adecuación de las familias de indicadores respecto de determinadas configuraciones de datos. En resumidas cuentas, no todas las configuraciones de datos son analizables con las mismas familias de indicadores, ya que la realidad (en este caso la realidad relacional) no es, analíticamente, una tábula rasa.

4. La ausencia de una semántica integrada en el ARS, lo que hace que, en la etapa de interpretación de los resultados, cada investigación tenga su propio nexo, a veces no reconocido, con instancias metateóricas que son las que realmente están suministrando explicaciones de base de los fenómenos que se analizan. Esto produce dos defectos contrarios: o los análisis no superan el nivel descriptivo, o se recurre a reglas generales o leyes no deducibles ni de la metodología ni la teoría de la cual hecha mano cada investigador.

5. La necesidad de validar éticamente la forma en que se interviene en una red, que es una temática no vinculada al componente técnico-analítico del ARS, pero que expresa una necesidad cada vez más acuciante de las investigaciones actuales. Además de rechazar una visión demasiado voluntarista e idealizada de esta perspectiva, como ya han hecho otros, intentamos mostrar la heterogeneidad de las intervenciones empíricas y el modo en que, lo queramos o no, siempre debemos saber por qué tomamos partido cuando llevamos a cabo una acción real basada en el conocimiento que provee el análisis de redes.

Al igual que con cualquier investigación no reticular, solo resulta útil pensar al ARS como soporte de acciones concretas en una comunidad o grupo. Esta perspectiva no constituye solo una colección de métodos de naturaleza formal, sino una manera de ver las relaciones sociales fuertemente marcada por la posibilidad de intervenir en ellas de diferente modo. Los problemas éticos derivados de la responsabilidad frente a esta acción o inacción son, una vez más, los mismos de cualquier investigación tradicional, pero además están inscriptos no sólo desde el momento en que se decide hacer algo con la información generada, sino que conciernen a la misma dinámica por la cual se producen los datos.

En la ilustración 13 se muestra, de manera integrada y concientemente reduccionista, las 5 etapas que hasta aquí describimos. En cada una de ellas contamos con un insumo, que es lo que ingresa a cada fase como dato del mundo o de un proceso anterior; un proceso, que es lo que se le aplica a aquello que ingresa; un producto, que es lo que el proceso genera al operar sobre un insumo, 
REDES- Revista hispana para el análisis de redes sociales

Vol.14,\#1, Junio 2008

http: // revista-redes. rediris.es

distintos factores de filtro que actúan sobre el producto en el momento del proceso, y finalmente aquello que es excluido en cada etapa como resultado de esa transformación producida en el input o insumo. Para tratar de incluir el componente iterativo y dialéctico de una investigación real, incluí los factores de error que se pueden producir en cada instancia, los cuales obligan a volver a las etapas anteriores con el fin de corregirlos.

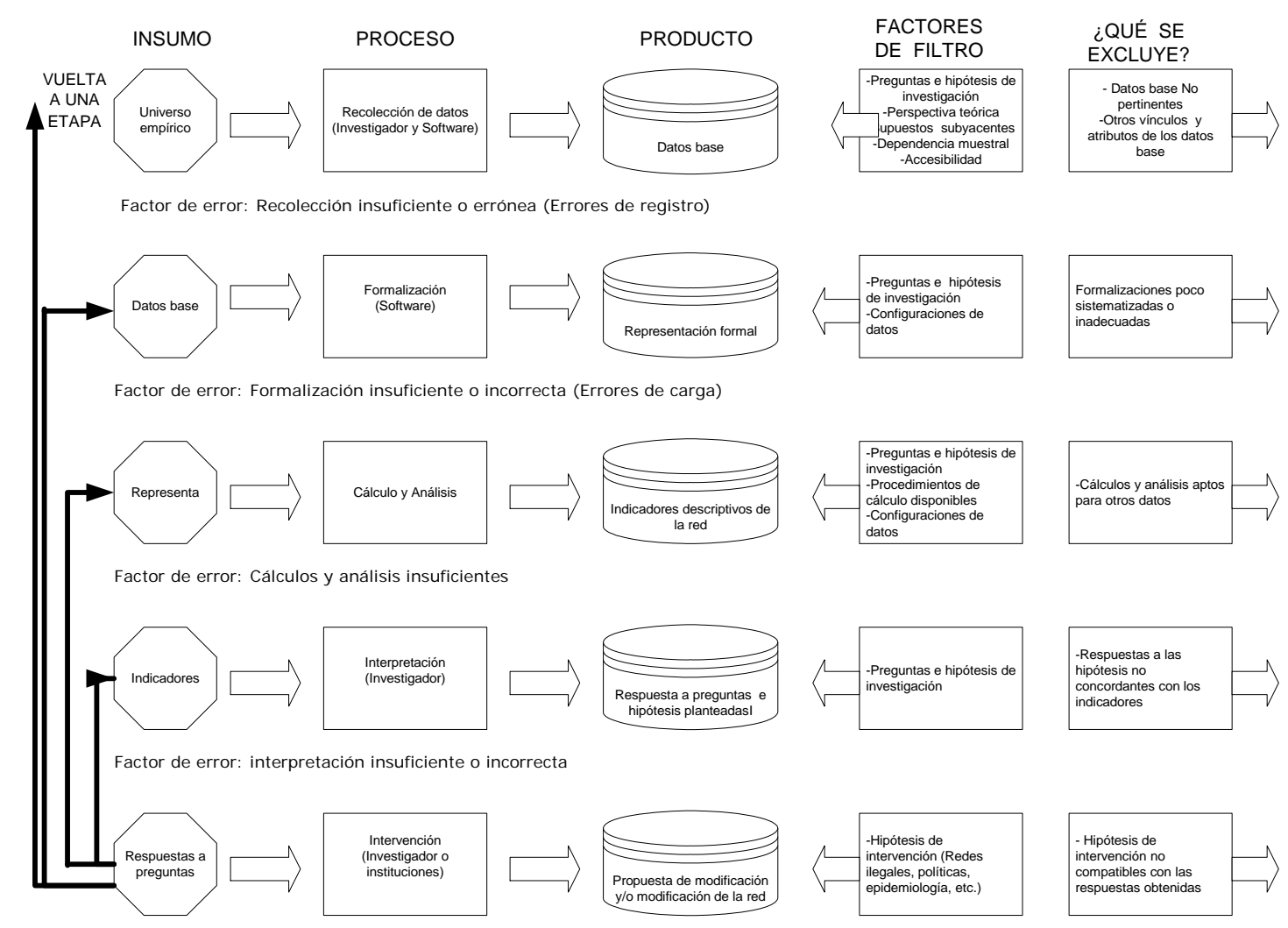

I lustración 13. . Planteo de etapas en una investigación típica de redes sociales.

\section{Referencias bibliográficas}

Analytictech, "Difussion" http://www.analytictech.com/networks/diffusion_htm (Visitada en Julio de 2007).

Center for AIDS Prevention Studies “¿Como afectan las redes sexuales a la transmisión del VIH/ETS? www.caps.ucsf.edu/espanol/hojas/pdf/redesFS.pdf (Visitada en Julio de 2007)

Giglia, Angela (2003). "Pierre Bordieu y la perspectiva reflexiva en las ciencias sociales", Centro de Investigaciones y Estudios Superiores en Antropología Social, México, en http://redalyc.uaemex.mx/redalyc/pdf/139/13901110.pdf (Visitada en Julio de 2007).

Borgatti, S.P., Everett, M.G. and Freeman, L.C. (2002). "Ucinet 6 for Windows", Harvard: Analytic Technologies. 
REDES- Revista hispana para el análisis de redes sociales

Vol.14,\#1, Junio 2008

http: // revista-redes. rediris.es

Bourdieu, Pierre (1992). Réponses, París: Seuil.

Breiger R. and Pattison P. (1986). "Cumulated social roles: The duality of persons and their algebras. Social Networks", 8, 215-256.

Connections http://www.insna.org/indexConnect.html (Visitada en Septiembre de 2007).

Darrow, William et al. (2006). "HIV Risk Reduction among Young Minority Adults in Broward County" J ournal of Health Care for the Poor and Underserved 17: 159-173

Versión electrónica en http://chua2.fiu.edu/faculty/darroww/reach2010/J ournal Publications/WW Hlaing Journal Published 2006.pdf (Visitada en Julio 2007).

Diario "Página 12", Nota "El día que la verdad ganó las calles" 2004, en http://www.pagina12.com.ar/diario/elmundo/4-32652-2004-03-14.html (Visitada en Octubre de 2007).

Federico, Ainhoa (2005). “Bases socio-metodológicas para el Análisis de Redes Sociales", Empiria. Revista de Metodología de Ciencias Sociales, 10, julio-diciembre, pp. 151-181.

Gilberto Giménez (1997). "La sociología de Pierre Bourdieu", Instituto de Investigaciones Sociales de la UNAM, en http://www.paginasprodigy.com/peimber/BOURDIEU.pdf (Visitada en Agosto de 2007).

Kent D. (1978). The rise of the Medici: Faction in Florence, 1426-1434. Oxford: Oxford University Press.

Ike Krieger "Cree su propio equipo de networking", en http://www.mujeresdeempresa.com/networking/networking060601.shtml)

(Visitada en Julio de 2007).

Hanneman, Robert "Introducción a los métodos del análisis de redes sociales", en http://wizard.ucr.edu/ rhannema/networks/text/textindex.html (Visitada en Junio 2007).

Hempel, Carl G. (1975). Confirmación, inducción y creencia racional. Buenos Aires: Paidós.

INSNA "International Network for Social Network Analysis", en http://www.insna.org/INSNA/insna_inf.html (Visitada en Septiembre de 2007).

Krebs Valdis, "Uncloaking Terrorist Networks" http://www.firstmonday.org/issues/issue7_4/krebs/ (Visitada en Julio de 2007).

Lozares, Carlos (2005). "Bases socio-metodológicas para el Análisis de Redes Sociales", Empiria. Revista de Metodología de Ciencias Sociales, 10, julio-diciembre, pp. 9-35.

Miceli, Jorge (2007). "Modelos de Percolación y difusión de ideas en Ciencias Sociales: Una clasificación provisoria", en Exploraciones en Antropologia y Complejidad, de la colección "Complejidad Humana”. Buenos Aires: Editorial SB. 
REDES- Revista hispana para el análisis de redes sociales

Vol.14,\#1, Junio 2008

http: // revista-redes. rediris.es

Miceli, Jorge y Guerrero, Sergio (2007). "Redes libres de escala y su uso en el análisis de datos etnográficos: el caso de la Comunidad Tehuelche del Chalía", de la colección "Complejidad Humana”, Buenos Aires: Editorial SB.

Miceli, Jorge y Guerrero, Sergio (2002). "Software de Genealogías" en Redes Revista Hispana de Redes Sociales Vol. 2 abril 2002, en http://revistaredes.rediris. es (Visitada en Julio de 2007).

Molina, José Luis y Schmidt, Samuel (2007). “El Análisis de redes sociales en HispanoAmérica: presente y futuro", XXIII Conferencia Internacional de Análisis de Redes Sociales en Cancún (México), en http://revistaredes.rediris.es/webredes/textos/Presente\%20y\%20futuro.htm (Visitada en Julio de 2007).

Padgett, John (1999). "John Padgett application for SFI Research Professor", en http://home.uchicago.edu/ jipadgett/papers/sfi/prop.pdf (Visitada en Julio de 2007).

Reynoso, Carlos (1998). “Corrientes en antropología contemporánea". Buenos Aires: Biblos.

Revista Redes http://revista-redes.rediris.es/ (Visitada en Septiembre de 2007).

Rivoir, Ana Laura (1999). "Redes Sociales: ¿Instrumento metodológico o categoría. sociológica?". Buenos Aires: Paidós, en http://www.lasociedadcivil.org/uploads/ciberteca/articulo_redes.pdf(visitada en Julio de 2007).

Smith, D and White, D. (1988). "Structure and dynamics of the global economy: Network analysis of international trade 1965-1980". Manuscrito no publicado.

Wasserman, S. and Faustm K. (1994). Social Network Analysis: Methods and Applications. Cambridge: Cambridge University Press. 